Article

\title{
Evolution of Hydrate Dissociation by Warm Brine Stimulation Combined Depressurization in the South China Sea
}

\author{
Jing-Chun Feng ${ }^{1,2}$, Gang $\mathrm{Li}^{1}$, Xiao-Sen $\mathrm{Li}^{1, *}$, Bo Li ${ }^{1,2}$ and Zhao-Yang Chen ${ }^{1}$ \\ 1 Guangzhou Center for Gas Hydrate Research, Chinese Academy of Sciences, Guangzhou 510640, \\ China; E-Mail: fengjc@ms.giec.ac.cn (J.-C.F.); ligang@ms.giec.ac.cn (G.L.); \\ libo@ms.giec.ac.cn (B.L.); chenzy@ms.giec.ac.cn (Z.-Y.C.) \\ 2 University of Chinese Academy of Sciences, Beijing 100083, China \\ * Author to whom correspondence should be addressed; E-Mail: lixs@ms.giec.ac.cn; \\ Tel.: +86-20-8705-7037; Fax: +86-20-8703-4664.
}

Received: 25 August 2013; in revised form: 9 October 2013 / Accepted: 11 October 2013 / Published: 21 October 2013

\begin{abstract}
To evaluate the gas production performance of the hydrate accumulations in the South China Sea, a numerical simulation with warm brine stimulation combined depressurization has been conducted. A dual horizontal well system is considered as the well configuration in this work. In order to reduce energy input and improve energy utilization, warm brine $\left(<30^{\circ} \mathrm{C}\right)$ instead of hot brine $\left(>50^{\circ} \mathrm{C}\right)$ is injected into the reservoir for hydrate dissociation. The effect of the intrinsic permeability of the hydrate reservoir, the salinity and the temperature of the injected brine to gas hydrate exploitation have been investigated. The numerical simulation results indicate that the average gas production rate $Q_{\text {avg }}$ is about $1.23 \times 10^{5} \mathrm{ST} \mathrm{m}^{3} /$ day for the entire hydrate deposit, which has the same order of magnitude compared with the commercially viable production rate. The injected brine can be pumped out from the upper production well directly after the hydrate between the two wells is dissociated completely. Thus, the effective region of heat and inhibitor stimulation is limited. The sensitivity analyses indicate that the dissociation rate of hydrate can be enhanced by increasing the temperature of the injected brine and raising the salinity of the injected brine. The parametric study of permeability shows that the hydrate of the reservoir with the larger permeability has a higher dissociation rate.
\end{abstract}


Keywords: numerical simulation; marine hydrate; warm brine stimulation; dual horizontal wells; South China Sea gas; production

\section{Nomenclature:}

$G \quad$ thermal gradient within the sea $\left({ }^{\circ} \mathrm{C} / \mathrm{m}\right)$

$H \quad$ depth of the sea water

$k \quad$ intrinsic permeability $\left(\mathrm{m}^{2}\right)$

$k_{\text {eff }} \quad$ effective permeability $\left(\mathrm{m}^{2}\right)$

$k_{\mathrm{rA}} \quad$ aqueous relative permeability $\left(\mathrm{m}^{2}\right)$

$k_{\mathrm{rG}} \quad$ gas relative permeability $\left(\mathrm{m}^{2}\right)$

$k_{\Theta \mathrm{C}} \quad$ thermal conductivity $(\mathrm{W} / \mathrm{m} / \mathrm{K})$

$k_{\Theta \mathrm{RD}} \quad$ thermal conductivity of dry porous medium $(\mathrm{W} / \mathrm{m} / \mathrm{K})$

$k_{\Theta \mathrm{RW}} \quad$ thermal conductivity of fully saturated porous medium $(\mathrm{W} / \mathrm{m} / \mathrm{K})$

$k_{\Theta I} \quad$ thermal conductivity of ice $(\mathrm{W} / \mathrm{m} / \mathrm{K})$

$M_{\mathrm{W}} \quad$ cumulative mass of produced water $(\mathrm{kg})$

$P \quad$ pressure (MPa)

$P_{\mathrm{B}} \quad$ initial pressure at base of $\mathrm{HBL}(\mathrm{MPa})$

$P_{0} \quad$ atmosphere pressure (MPa)

$P_{\mathrm{W}} \quad$ pressure at the well (MPa)

$P_{\mathrm{W} 0} \quad$ initial pressure at the well $(\mathrm{MPa})$

$Q \quad$ injected heat (J)

$Q_{\text {avg }} \quad$ average gas production rate ( $\mathrm{ST} \mathrm{m}^{3} /$ day $/ \mathrm{m}$ of well)

$Q_{\mathrm{W}} \quad$ average water production rate $(\mathrm{kg} / \mathrm{day} / \mathrm{m}$ of well)

$Q_{\text {inj }} \quad$ heat injection rate (W/m of well)

$r \quad$ radius $(\mathrm{m})$

$R_{\mathrm{GW}} \quad$ the gas to water production ratio $\left(\mathrm{ST} \mathrm{m}^{3}\right.$ of $\mathrm{CH}_{4} / \mathrm{m}^{3}$ of $\mathrm{H}_{2} \mathrm{O}$ )

$S \quad$ phase saturation

$t \quad$ time (days)

$T \quad$ temperature $\left({ }^{\circ} \mathrm{C}\right)$

$T_{0} \quad$ the temperature of the sea floor

$T_{\mathrm{W}} \quad$ injected warm water temperature $\left({ }^{\circ} \mathrm{C}\right)$

$T_{\mathrm{B}} \quad$ initial temperature at the base of $\mathrm{HBL}\left({ }^{\circ} \mathrm{C}\right)$

$T_{\mathrm{T}} \quad$ initial temperature at the top of $\operatorname{HBL}\left({ }^{\circ} \mathrm{C}\right)$

$W \quad$ pump work (J)

$x, y, z \quad$ Cartesian coordinates (m)

$S_{\mathrm{H}} \quad$ hydrate saturation

$S_{\mathrm{G}} \quad$ gas saturation

$X_{\mathrm{S}} \quad$ the mass fraction of salt in the aqueous phase

$x_{A}^{\imath} \quad$ mole fraction of the inhibitor in the aqueous phase

$x_{A, r} \quad$ reference mole fraction of the inhibitor in the aqueous phase (K)

$\Delta T_{D} \quad$ inhibitor-induced temperature depression $(\mathrm{K})$ 


$\begin{array}{ll}\Delta T_{D, r} & \text { temperature depression at the reference mole fraction } x_{A, r}^{i} \\ \Delta H_{\mathrm{c}} & \text { combustion enthalpy of produced methane }(\mathrm{J}) \\ \Delta P_{\mathrm{W}} & \text { driving force of depressurization, } P_{\mathrm{W} 0}-P_{\mathrm{W}}(\mathrm{MPa}) \\ \Delta x & \text { discretization along the } x \text {-axis }(\mathrm{m}) \\ \Delta y & \text { discretization along the } y \text {-axis (m) } \\ \Delta z & \text { discretization along the } z \text {-axis (m) } \\ \phi & \text { porosity } \\ \eta & \text { energy efficiency } \\ \lambda & \text { van Genuchten exponent (Table 1) } \\ \text { Subscripts } & \text { and Superscripts } \\ 0 & \text { denotes initial state } \\ \text { A } & \text { aqueous phase } \\ \text { B } & \text { base of HBL } \\ \text { cap } & \text { capillary } \\ \mathrm{G} & \text { gas phase } \\ \mathrm{H} & \text { solid hydrate phase }\end{array}$

\section{Introduction}

\subsection{Background}

Natural gas hydrates are crystalline solids composed of water and gas, in which the gas molecules (guests) are trapped in the water cavities (hosts). The water cavities are comprised of hydrogen-bonded water molecules. Methane, ethane, propane, and carbon dioxide are recognized as the typical natural gas molecules [1]. Given the restricted conventional fossil fuel reserves and the ever-increasing global energy demand, natural gas hydrate is regarded as a potential energy resource because the current estimated amount of natural gases encaged in gas hydrate is vast [2]. It is generally accepted that gas hydrate exists widely in oceanic sediments and the permafrost region where the conditions of high pressure and low temperature are favorable for its formation and stability [3].

The study on how to decompose the solid hydrate economically and effectively is a crucial issue in gas hydrate exploitation. The major methods of hydrate dissociation include depressurization [4,5], thermal stimulation [6], and the use of thermodynamic inhibitors [7]. On account of the fact that each approach has its pros and cons, the combined utilization of depressurization and thermal stimulation has been proven to be favorable for hydrate dissociation [8]. Hot brine stimulation combines the advantages of thermal stimulation and inhibitor stimulation. Li et al. [9] indicated that the hot brine stimulation experiment could obtain a higher energy efficiency than that using hot water stimulation. Subsequently, Li et al. [10] further indicated that the hydrate dissociation rate increased with the increase of salinity. Recently, Moridis et al. [11] showed that the dual horizontal well system is better than the single horizontal well layout because of preferable heat transference. Much research in recent 
years has focused on hydrate dissociation under hot water stimulation, but few studies have investigated warm brine stimulation, especially with dual horizontal wells.

\subsection{Oceanic Hydrates and the Hydrates in the South China Sea}

As the oceans comprise $70 \%$ of the Earth's surface, the oceanic hydrate accumulations constitute approximately $99 \%$ of the total gas hydrate resource [2]. The Gulf of Mexico and the Nankai Trough are considered as two models for evaluating the oceanic gas hydrate prospects [12]. Japan obtained gas from the oceanic hydrates by depressurization in the Nankai Trough in March of 2013 [13], which was the world's first successful production of gas from hydrate reservoir at the bottom of the ocean. In the northern Gulf of Mexico, a logging-while-drilling expedition was conducted in April and May of 2009 [14]. The drilling tests showed that high $S_{\mathrm{H}}$ (from $50 \%$ to $90 \%$ ) hydrate samples were acquired in two wells in Walker Ridge 313 and two in Green Canyon 955. Because of the limited long-term production data from hydrate-bearing accumulations, numerical simulation has been regarded as an effective way in evaluating gas production [15].

Nowadays, research results indicate that abundant gas hydrate exists in the continental slope of the South China Sea (SCS, Figure 1) [16-18]. In May, 2007, gas hydrate samples were discovered in the Shenhu Area of the SCS during the scientific expedition carried out by the China Geological Survey.

Figure 1. Map of the South China Sea [16].

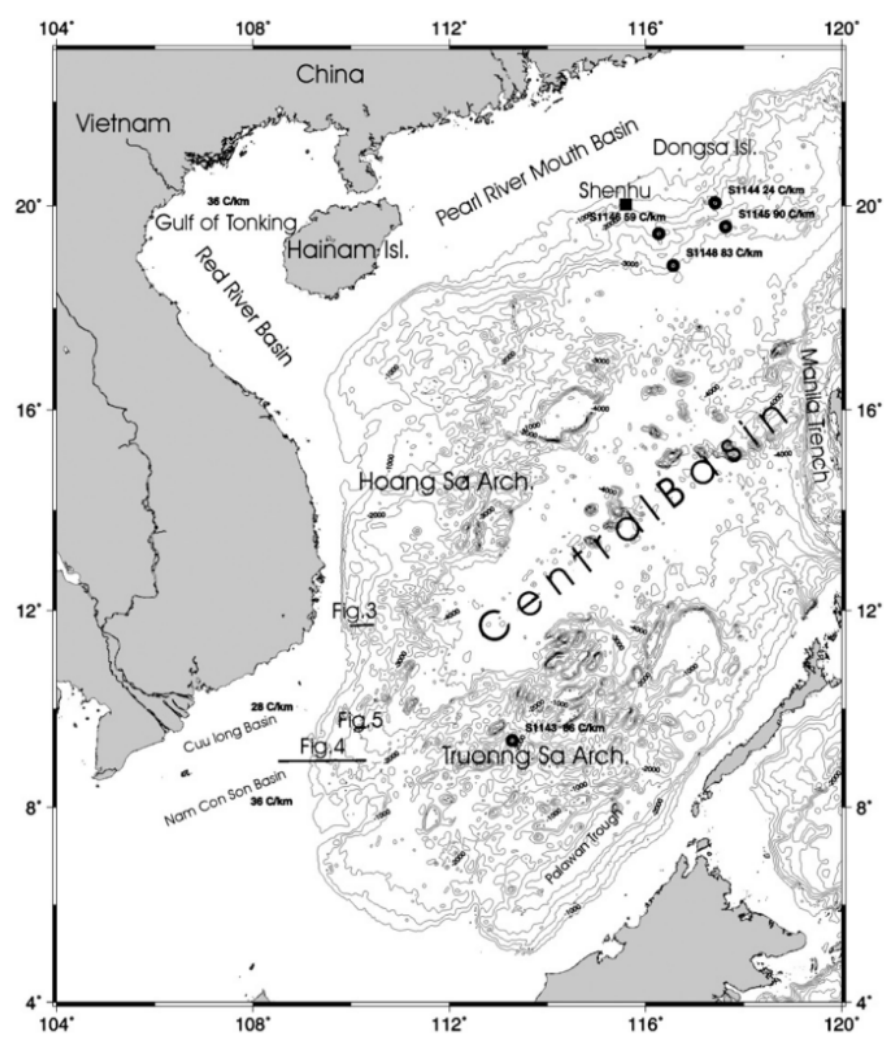

Li et al. [19] and $\mathrm{Su}$ et al. [20] established their models based on the measurement data from different sites in the Shenhu Area. They both used the huff and puff method to investigate the gas production performance from the hydrate sediments with a horizontal well and a vertical well respectively. The results demonstrate that the gas production relies on the initial intrinsic permeability, 
the temperature, the hydrate saturation of the Hydrate-Bearing Layer $(\mathrm{HBL})$, and the temperature of the well. However, the gas production rates are several orders of magnitude less than acceptable standards of commercial viable gas production.

\subsection{Objectives}

This study aims to evaluate the gas production potential from hydrate accumulations in the SCS by numerical simulation. A model of gas hydrate reservoir is established from the available data in the SCS $[16,21,22]$. The well configuration is the dual horizontal wells in this study, like the work of Moridis et al., the lower horizontal well is set as the injection well and the upper one is the production well. In addition, the warm brine $\left(<30^{\circ} \mathrm{C}\right)$ instead of hot brine $\left(>50{ }^{\circ} \mathrm{C}\right)$ is applied in this work for improving energy utilization. The gas production of the hydrate reservoir is investigated by combining the depressurization, the thermal stimulation, and the inhibitor stimulation. The sensitivities of gas production to the injected temperature, the salinity of the injected brine, and the intrinsic permeability of the hydrate reservoir are also investigated.

\section{Production Schemes and Well Design}

\subsection{Dissociation Method}

Moridis et al. [23] reported that the Class 1 hydrate deposit was characterized by a HBL and an underlying two-phase fluid zone with free gas. Similarly, the Class 2 hydrate deposit consists of a HBL and an underlying zone of mobile water. The hydrate accumulation in the SCS is similar to the Class 3 deposit which involves only a HBL without underlying mobile fluid zones, and this kind of hydrate reservoir is regarded as "challenging" for gas production [24].

Depressurization has been widely used in gas hydrate studies for its technical viability and economic advantage [4,25]. Konno et al. [26] employed the numerical simulator MH21-HYDRES to evaluate the gas productivity of the four different kinds of hydrate reservoir by the depressurization method with a single vertical well. The results showed that depressurization was the most feasible technique in the Class 1 hydrate reservoir. Whereas the depressurization-induced method was unattractive for the Class 3 hydrate reservoir because of the absence of a free gas zone underneath the HBL. Earlier studies verified that the combined utilization of depressurization and thermal stimulation was favorable for gas production. However, simple hot water injection seemed to be ineffective due to the energy loss [23]. In this work, the gas production is conducted by combining warm brine stimulation and depressurization with dual horizontal wells.

\subsection{Well Configuration}

The investigation of Moridis et al. [27] indicated that the utilization of a horizontal well resulted in a dramatic increase of gas production from Class 2 and the Class 3 reservoirs compared with vertical wells. Thus a dual horizontal wells in the same vertical plane layout was applied in this study. The warm brine is injected into the lower horizontal well and the fluids are produced from the upper one under constant pressure conditions. 
In this model, the distance between two wells is $20 \mathrm{~m}$ (shown in Figure 2a). The radius $r_{\mathrm{W}}$ of the wells are both $0.1 \mathrm{~m}$. There are 12 grooves located along the circumference of the wells [28]. The porosity of the wellbores is assumed to be 1.0. The permeability $k$ and the capillary pressure $P_{\text {cap }}$ are set as $5.0 \times 10^{-9} \mathrm{~m}^{2}$ (5000 Darcies) and 0, respectively [19].

Figure 2. (a) Schematic of the marine hydrate reservoir in the South China Sea; (b) The corresponding 2-D hybrid mesh.

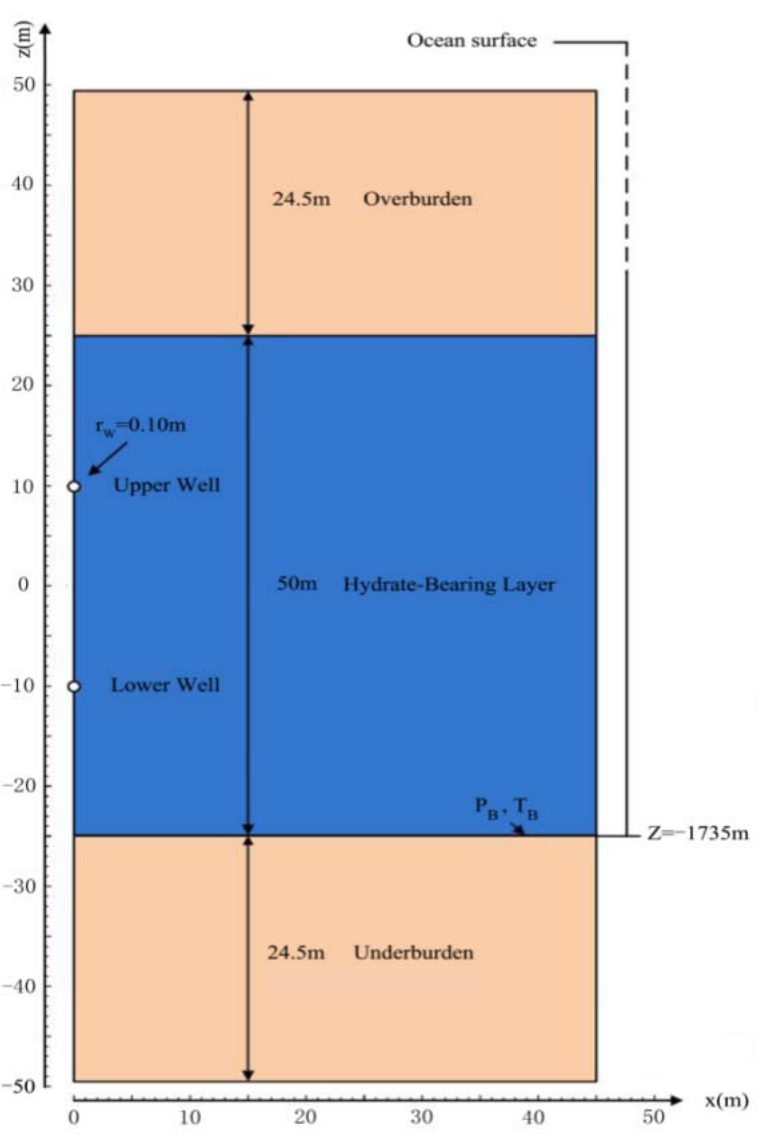

(a)

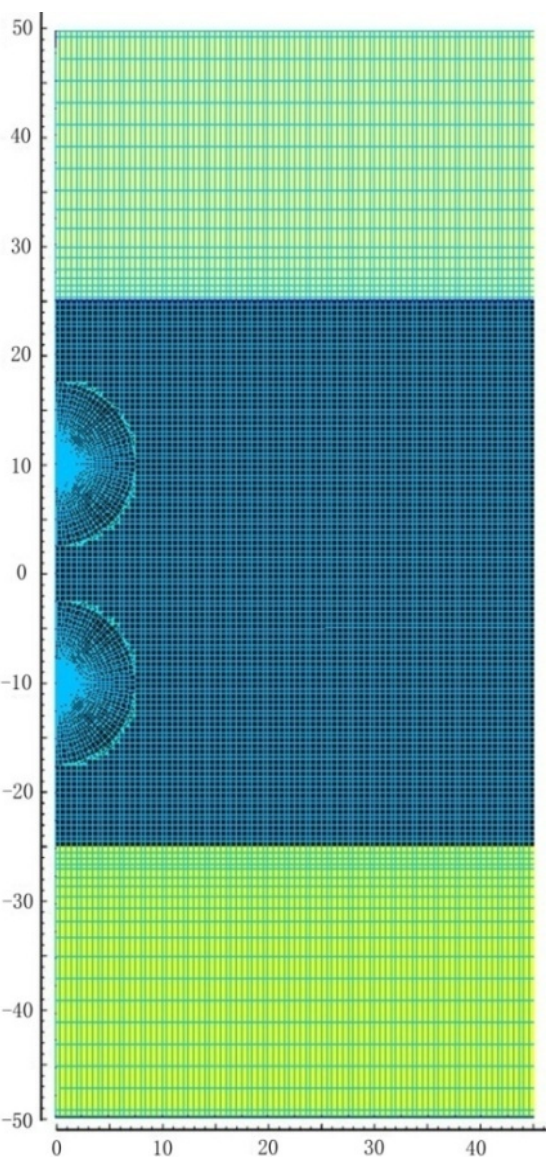

(b)

\section{Numerical Models and Simulation Method}

\subsection{Geometry, Domain Discretization, and System Properties}

Both the serial and parallel versions of the TOUGH+HYDRATE code [29,30] are applied in this study to perform the numerical simulation. In order to investigate the dissociation performance of the oceanic hydrate, the geologic parameters of this study is in accordance with the hydrate accumulations of the SCS. It is necessary to make reasonable estimations of the media properties since the field measurement data are quite limited. In this model, methane is assumed to be the only hydrate-forming gas.

The geometry and the configuration of the hydrate deposit with two parallel horizontal wells are shown in Figure 2a. The $50 \mathrm{~m}$-thick HBL is located in the middle of the deposit. On the top of the HBL, a permeable overburden exists, and a permeable underburden lies under the HBL as well, which allows fluids flow and heat exchange in them. The thickness of the overburden and underburden both are $24.5 \mathrm{~m}$, which are sufficient to permit accurate heat exchange, mass exchange, and pressure transfer in 
the hydrate accumulation. As seen in Figure 2, the total thickness of the whole domain simulated in this study is $99 \mathrm{~m}$. In order to minimize the gas escape from the overburden and underburden, the two parallel wells are situated at $z=10 \mathrm{~m}$ and $z=-10 \mathrm{~m}$, respectively. This work set a simulation region of $0 \leq x \leq 45 \mathrm{~m}$ which indicates a well spacing of $90 \mathrm{~m}$ for symmetry, and there is no heat and mass flow at $x=0$ and $x=45 \mathrm{~m}$.

As shown in Figure $2 \mathrm{~b}$, a 2-D hybrid mesh $(y=1 \mathrm{~m})$ is applied to conduct the simulation. This model can describe the performance of the entire $1000 \mathrm{~m}$-long well. The mesh includes 12,228 elements, and 12,008 of them are active elements. The inactive elements belong to the boundary and steel gridblocks. The overburden and underburden are set as inactive boundary cells which meet constant temperature and pressure. For the sake of accurate prediction, $\Delta z$ is finely discretized to be less than $0.5 \mathrm{~m}$ along the $z$ axis in the top of the underburden, the HBL, and the bottom of the overburden. And the discretization far from the HBL becomes coarse. The regions around the horizontal wells are discretized to be pretty fine in order to describe the temperature and pressure precisely. The area of $r<7.5 \mathrm{~m}$ around the two wells are discretized into refined cylindrical meshes to accurately capture the complex physical and chemical processes. The first cylindrical layer $(\mathrm{r}=0.1 \mathrm{~m})$ has six gridblocks standing for the grooves of the well, and the remaining ones are the impermeable steel elements representing the wall of the well. The warm brine is injected into the HBL at a constant rate $Q_{\text {inj }}$ from the six gridblocks which act as source terms in the injection well, while the six gridblocks in the upper well perform as sink terms. The discretization in the core of the circle is very fine, but it gets coarser in the direction of the radius. Supposing the hydrate dissociation with inhibitors in equilibrium state [29], the number of the coupled equations in this simulation is 48,032 , which is from multiplying by 12,008 (active cells) and 4 (the equations of per cell include the mass balance equations of gas, water and salt, as well as the energy balance equation $[31,32]$ ).

\subsection{Initial Conditions.}

According to the available data [33], the depth of seawater $H$, the geothermal gradient $G$, and the salinity of the seawater $X_{\mathrm{S}}$ are selected as $1500 \mathrm{~m}, 45 \mathrm{~K} / \mathrm{km}$, and $3.50 \%$, respectively. The remaining parameters used in this work are shown in Table 1.

Since the actual temperature and pressure measurements are unavailable, the T- and P-distribution of the system are estimated by the following methods. On the basis of the field measurements $[16,21,22]$, the temperature of the sea floor $T_{0}$ is selected as $277.15 \mathrm{~K}$. Then the T-distribution of the whole system including the temperatures $T_{\mathrm{T}}$ (at the top of the HBL) and $T_{\mathrm{B}}$ (at the bottom of the HBL, at $z=-1735 \mathrm{~m}$ ) are estimated in the light of the two basic parameters $\left(T_{0}\right.$ and $\left.G\right)$. The initial temperature of $T_{\mathrm{B}}$ is 288.28 $\mathrm{K}$ (shown in Table 1). Afterwards, the hydrate pressure and temperature (P-T) equilibrium curve is employed to determine the lower restriction of $P_{\mathrm{B}}$ at the bottom of the HBL for keeping the steady state of the initial HBL. In this study, $P_{\mathrm{B}}$ is $18.25 \mathrm{MPa}$ which is initialized a bit higher than the equilibrium pressure to guarantee the hydrate stability. Such system is easy to destabilize under thermal stimulation or depressurization [19].

Finishing initializing the $\mathrm{P}$ and $\mathrm{T}$ distributions in each gridblock (shown in Figure $2 \mathrm{~b}$ ), the other initial conditions, such as the saturation of gas $\left(S_{\mathrm{G}}\right)$, the saturation of water $\left(S_{\mathrm{A}}\right)$, and the salinity of brine $\left(X_{\mathrm{S}}\right)$ in the reservoir, can be achieved by another short simulation. As displayed in Table 1, the $S_{\mathrm{H}}$ 
and the $S_{\mathrm{A}}$ in the HBL, and the $S_{\mathrm{A}}$ of the overburden and underburden are $0.451,0.549$, and 1.0, respectively, which means no free gas existing in the whole system. The salinity of water in the model is 0.350 . After completing initialization, any condition of the entire system will keep unchangeable unless a disturbance from outside occurs.

Table 1. Physical properties and simulation models in marine deposit of the South China Sea.

\begin{tabular}{|c|c|c|c|}
\hline Parameter & Value & Parameter & Value \\
\hline Thickness of HBL & $50 \mathrm{~m}$ & Capillary pressure model [34] & $\begin{array}{l}P_{\text {cap }}=-P_{01}\left[\left(S^{*}\right)^{-1 / \lambda}-1\right]^{1-\lambda} \\
S^{*}=\left(S_{\mathrm{A}}-S_{\mathrm{irA}}\right) /\left(S_{\mathrm{mxA}}-S_{\mathrm{irA}}\right)\end{array}$ \\
\hline Thickness of OB and UB & $24.5 \mathrm{~m}$ & $S_{\text {irA }}$ & 0.29 \\
\hline $\begin{array}{l}\text { Position of HBL below } \\
\text { the ground }\end{array}$ & $160.5 \mathrm{~m}$ & $\lambda$ & 0.45 \\
\hline distance between two wells & $20 \mathrm{~m}$ & $P_{01}$ & $10^{5} \mathrm{~Pa}$ \\
\hline $\begin{array}{l}\text { Initial } P_{\mathrm{B}} \text { and } T_{\mathrm{B}} \\
\text { (at base of } \mathrm{HBL} \text { ) }\end{array}$ & $18.25 \mathrm{MPa}, 288.28 \mathrm{~K}$ & Relative permeability Model & $\begin{array}{c}k_{\mathrm{rA}}=\left(S_{\mathrm{A}}{ }^{*}\right)^{n} \\
k_{\mathrm{rG}}=\left(S_{\mathrm{G}}{ }^{*}\right)^{n G} \\
S_{\mathrm{A}}{ }^{*}=\left(S_{\mathrm{A}}-S_{\mathrm{irA}}\right) /\left(1-S_{\mathrm{irA}}\right) \\
S_{\mathrm{G}}{ }^{*}=\left(S_{\mathrm{G}}-S_{\mathrm{irG}}\right) /\left(1-S_{\mathrm{irA}}\right)\end{array}$ \\
\hline Gas composition & $100 \% \mathrm{CH}_{4}$ & $P_{01}$ & $10^{5} \mathrm{~Pa}$ \\
\hline \multirow[t]{3}{*}{$\begin{array}{c}\text { Composite thermal } \\
\text { conductivity model }[29,35]\end{array}$} & \multirow[t]{3}{*}{$\begin{array}{c}k_{\Theta \mathrm{C}}=k_{\Theta \mathrm{RD}}+\left(S_{\mathrm{A}}^{1 / 2}+S_{\mathrm{H}}^{1 / 2}\right) \\
\left(k_{\Theta \mathrm{RW}}-k_{\Theta \mathrm{RD}}\right)+\phi S_{\mathrm{I}} k_{\Theta \mathrm{I}}\end{array}$} & Relative permeability Model & $\begin{array}{c}k_{\mathrm{rA}}=\left(S_{\mathrm{A}}{ }^{*}\right)^{n} \\
k_{\mathrm{rG}}=\left(S_{\mathrm{G}}{ }^{*}\right)^{n G} \\
S_{\mathrm{A}}{ }^{*}=\left(S_{\mathrm{A}}-S_{\mathrm{irA}}\right) /\left(1-S_{\mathrm{irA}}\right) \\
S_{\mathrm{G}}{ }^{*}=\left(S_{\mathrm{G}}-S_{\mathrm{irG}}\right) /\left(1-S_{\mathrm{irA}}\right)\end{array}$ \\
\hline & & $n$ & 3.572 \\
\hline & & $n_{\mathrm{G}}$ & 3.572 \\
\hline Sea floor temperature $T_{0}$ & $277.15 \mathrm{~K}$ & \multirow{3}{*}{ Relative permeability Model } & $k_{\mathrm{rA}}=\left(S_{\mathrm{A}}^{*}\right)^{n}$ \\
\hline Geothermal gradient $G$ & $0.045 \mathrm{~K} / \mathrm{m}$ & & $\begin{array}{c}k_{\mathrm{rG}}=\left(S_{\mathrm{G}}\right) \\
S_{\mathrm{A}}{ }^{*}=\left(S_{\mathrm{A}}-S_{\mathrm{irA}}\right) /\left(1-S_{\mathrm{irA}}\right)\end{array}$ \\
\hline Water salinity (mass fraction) & $3.50 \%$ & & $S_{\mathrm{G}}^{*}=\left(S_{\mathrm{G}}-S_{\mathrm{irG}}\right) /\left(1-S_{\mathrm{irA}}\right)$ \\
\hline \multirow{2}{*}{$\begin{array}{c}\text { Intrinsic permeability } \\
k_{\mathrm{x}}=k_{\mathrm{y}}=k_{\mathrm{z}}(\mathrm{HBL}, \mathrm{OB} \& \mathrm{UB})\end{array}$} & \multirow{2}{*}{$\begin{array}{l}7.5 \times 10^{-14} \mathrm{~m}^{2} \\
(=0.075 \mathrm{mD})\end{array}$} & $n$ & 3.572 \\
\hline & & $n_{\mathrm{G}}$ & 3.572 \\
\hline Porosity $\phi$ (all formations) & 0.40 & $S_{\mathrm{irG}}$ & 0.05 \\
\hline Initial hydrate saturation & $S_{\mathrm{H}}=0.451$ & $S_{\text {irA }}$ & 0.30 \\
\hline
\end{tabular}

\section{Results and Discussion}

\subsection{Dual Horizontal Wells Design with Warm Brine Injection}

The simulation of gas production performance in the oceanic hydrate accumulation of the SCS is conducted by combining warm brine stimulation and depressurization. For the sake of evaluating the influence of the water salinity on the gas production, three cases with different salinities of the injected brine (salinity $=3.5 \%, 5.0 \%$, and $7.0 \%$ ) are carried out in this work. In addition, gas production is investigated through cases with different temperatures of the injected brine, and with the different intrinsic permeabilities of the hydrate reservoir. 
As shown in Figure 3, points A1 to D1 represent the actual pressures of the bottom of the overburden, the upper wellbore, the lower wellbore, as well as the top of the underburden; and points A2 to D2 stand for the corresponding equilibrium pressures of the same location.

Figure 3. Profiles of the depressurization situation of the marine hydrate reservoir in the South China Sea.

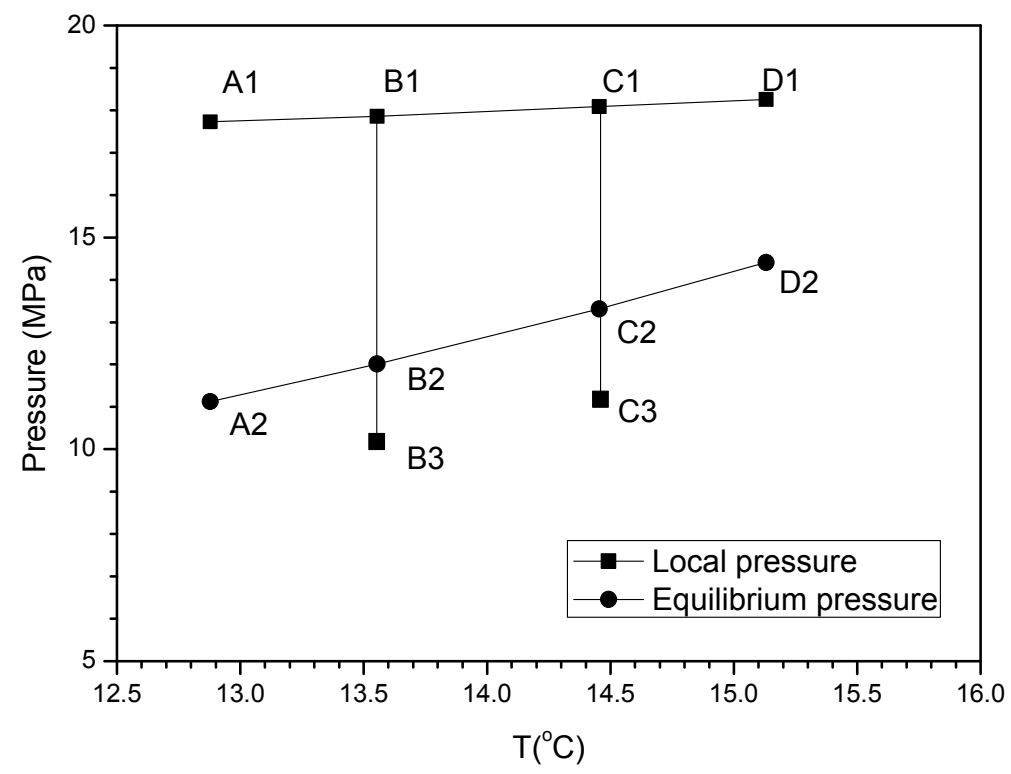

Pumping out the mass of the reservoir from the upper well is operated at a constant pressure. The constant pressure $P_{\mathrm{W}}$ of the upper wellbore is $10.00 \mathrm{MPa}$ (point B3 in Figure 3). And the initial pressure $P_{\mathrm{W} 0}$ of the upper well bore is $17.88 \mathrm{MPa}$ (point $\mathrm{B} 1$ in Figure 3 ). The pressure drop $\Delta P_{\mathrm{W}}$ $\left(\Delta P_{\mathrm{W}}=P_{\mathrm{W} 0}-P_{\mathrm{W}}\right)$ is $0.44 P_{\mathrm{W} 0}$ in the depressurization process. The equilibrium pressure $P_{\mathrm{Weq}}$ (point B2 in Figure 3) of the upper wellbore is $12.01 \mathrm{MPa}$, which means that the hydrate starts to decompose only when the pressure decreases below 12.01 MPa. Consequently, the effective hydrate dissociation driving force $\Delta P_{\mathrm{W}}$ of the depressurization process is just $0.17 P_{\text {Weq. }}$.

Considering that the pores in the HBL are filled with hydrate and water without free gas, the pressure of the lower wellbore may rise to an extraordinary high level if the warm brine is poured into the lower well at the start of the simulation. For the sake of operation safety, 40 days of depressurization is conducted in the lower well to decompose the hydrate around the wellbore, and the pressure of the lower wellbore is set as $11.00 \mathrm{MPa}$ (point C3 in Figure 3). Then the warm brine is injected into the lower well at a constant injection rate.

\subsection{The Reference Case and the Gas and Water Production}

In the reference case, the initial pressure and temperature of the HBL at $z=10 \mathrm{~m}$ (the location of the production well) are $17.88 \mathrm{MPa}$ and $12.01{ }^{\circ} \mathrm{C}$, respectively. At the beginning, a constant-pressure production in both of the horizontal wells is applied in the first 40 days. The pressures of the upper wellbore and the lower wellbore are set as $10.00 \mathrm{MPa}$ and $11.00 \mathrm{MPa}$, respectively. Since the 41st day, the warm brine is injected into the lower well, and the injection rate is $21.6 \mathrm{~kg} / \mathrm{s}$ (1000 m length of the well). Meanwhile, the upper well is kept at the same depressurization situation as that in the first 
40 days. The temperature of the injected brine is $28{ }^{\circ} \mathrm{C}$. The salinity of the brine is $3.5 \%$. And the intrinsic permeability of the hydrate reservoir is $75 \mathrm{mD}$.

Figure 4 reveals the evolution of the volumetric rates ( $1 \mathrm{~m}$ of the horizontal well) of $\mathrm{CH}_{4}$ in the total gas production $\left(Q_{\mathrm{PT}}\right)$ at the well, the $\mathrm{CH}_{4}$ production rate in the gas phase $\left(Q_{\mathrm{PG}}\right)$, the gas releasing rate from hydrate dissociation $\left(Q_{\mathrm{R}}\right)$, the aqueous phase mass flow rate $\left(Q_{\mathrm{W}}\right)$, and their dependence on the salinity of the injected brine. In this section, the description of gas and water production is only about the reference case.

Figure 4. Volumetric rate of $\mathrm{CH}_{4}$ production in the total gas production at the well $Q_{\mathrm{PT}}$, the $\mathrm{CH}_{4}$ production rate in the gas phase $Q_{\mathrm{PG}}$, the gas releasing rate from hydrate dissociation $Q_{\mathrm{R}}$, and the aqueous phase mass flow rate $Q_{\mathrm{W}}$, and their dependence on the salinity of the injected brine during hydrate dissociation.

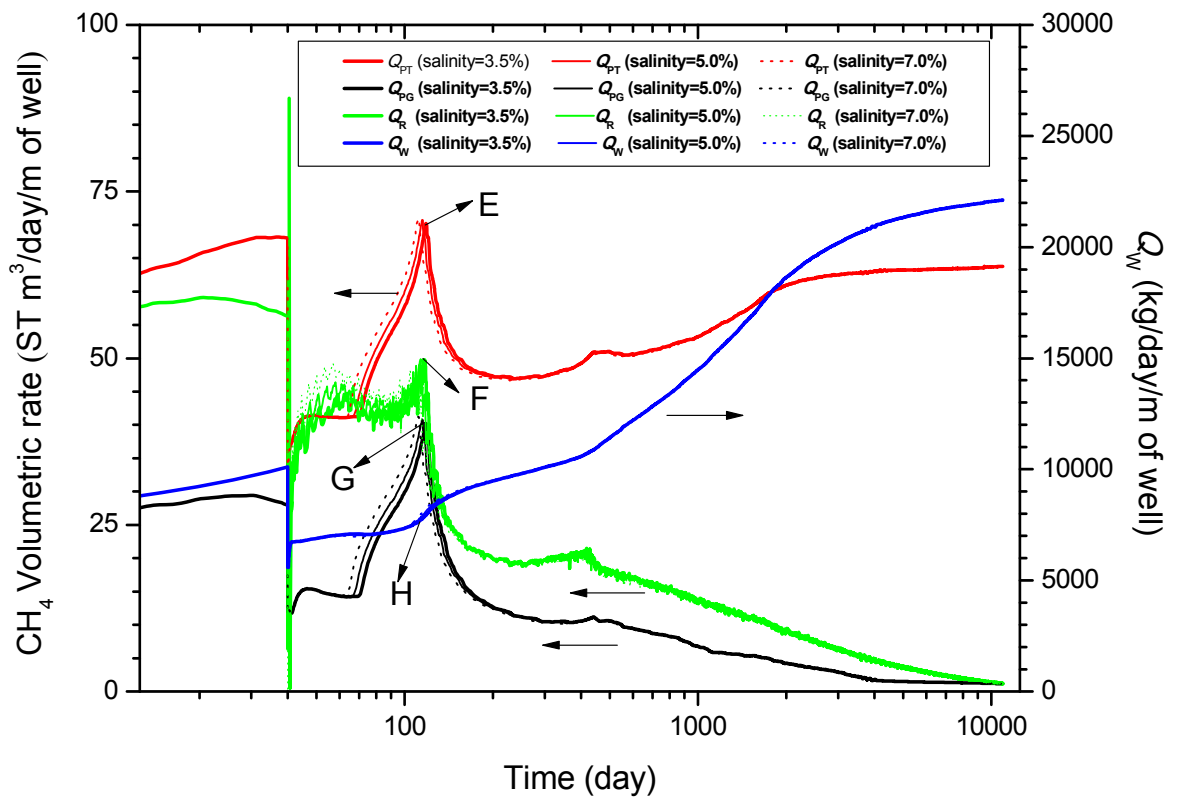

As seen in Figure 4, during the initiatory 40 days, $Q_{\mathrm{R}}$ is characterized by increasing in the beginning, and descending after about 20 days. The increasing trend results from the hydrate dissociation when the reservoir pressure drops below the equilibrium pressure. Hydrate dissociation is an endothermic reaction, but the sensible heat provided from the hydrate reservoir is limited in the absence of inputting external energy, causing the reduction of hydrate dissociation rate. The change of $Q_{\mathrm{PG}}$ is similar to that of $Q_{\mathrm{R}}$, while the descending point of $Q_{\mathrm{PG}}$ comes a little later than that of $Q_{\mathrm{R}}$, indicating that the produced gas mainly originates from the released gas. In this period, $Q_{\mathrm{PT}}$ and $Q_{\mathrm{W}}$ keep monotonically increasing, suggesting that the hydrate is dissociated continuously under the driving force of depressurization. In the course of the initial 40 days simulation, $Q_{\mathrm{PG}}$ is much smaller than $Q_{\mathrm{PT}}$ and $Q_{\mathrm{R}}$, because a large portion of the produced gas is dissolved in the brine, instead of maintaining in the free gas phase.

From the 41st day on, warm brine is injected into the hydrate reservoir from the lower horizontal well. Meanwhile, the produced gas and water are pumped out from the upper well. The profiles of Figure 4 change abruptly when warm brine is injected into the hydrate reservoir. At this point, a considerable amount of hydrate is dissociated under the effect of thermal stimulation, which leads to 
a peak value of $Q_{\mathrm{R}}$. Nonetheless, it's evident that $Q_{\mathrm{W}}, Q_{\mathrm{PT}}$, and $Q_{\mathrm{PG}}$ decrease drastically after this point. This is because that the lower production well is changed to be the injection well, causing that the fluids are just produced out from one well. Afterwards, the remaining hydrate is dissociated under the synergistic effects of depressurization, thermal stimulation, and inhibitor stimulation, resulting in the increase of gas and water production rates. After about 78 days of warm brine injection, $Q_{\mathrm{PT}}, Q_{\mathrm{PG}}$, and $Q_{\mathrm{R}}$ achieve the maximum value (at point E, F, G, respectively). At point F, $Q_{\mathrm{R}}$ reaches the peak value (49.5 $\mathrm{ST} \mathrm{m}^{3}$ per day), and then declines to a very low level (about $1.2 \mathrm{ST} \mathrm{m}^{3}$ per day) over time. The change of $Q_{\mathrm{PG}}$ keeps in the same trend with that of $Q_{\mathrm{R}}$, and $Q_{\mathrm{PG}}$ is less than $Q_{\mathrm{R}}$ all the time, suggesting that a portion of the released gas is dissolved in the liquid phase. $Q_{\mathrm{W}}$ slowly increases before the inflection point (point $\mathrm{H}$ ). In the following time, it tends to grow rapidly. The abrupt increase of water production rate is because that the two horizontal wells are connected after the hydrates between the two wells are dissociated. Subsequently, the injected warm brine can be pumped out from the production well directly. $Q_{\mathrm{PT}}$, which contains the $Q_{\mathrm{PG}}$ and the gas dissolved in the liquid, increases to $70 \mathrm{ST} \mathrm{m}^{3}$ per day (at point E), because of the growing of $Q_{\mathrm{PG}}$ and $Q_{\mathrm{W}}$. Although $Q_{\mathrm{PG}}$ keeps declining until the end of simulation, $Q_{\mathrm{PT}}$ gradually increases to a constant rate (about $63 \mathrm{ST} \mathrm{m}^{3}$ per day), because the change of $Q_{\text {PT }}$ mainly depends on the increase of $Q_{\mathrm{W}}$. After 30 years of production, the average gas production rate $Q_{\text {avg }}$ is about $1.23 \times 10^{5} \mathrm{ST} \mathrm{m}^{3} /$ day for the whole hydrate reservoir (calculated by multiplying the simulation results with 2000). Comparing with the commercially viable production rate $\left(2.8 \times 10^{5} \mathrm{ST} \mathrm{m}^{3} /\right.$ day $)$ in the Gulf of Mexico [11], the gas production in this simulation seems to be promising. However, the corresponding water production rate $Q_{\mathrm{W}}$ is about $3.98 \times 10^{7} \mathrm{~kg} / \mathrm{day}$, which is massive and uneconomic for exploitation.

\subsection{Energy Efficiency and Gas-to-Water Ratio}

Figure 5 displays the evolution of the gas-to-water ratios $R_{\mathrm{GW}}$, the energy efficiency $\eta$, and their dependence on the salinity of the injected brine in the entire simulation process. In this section, only the reference case is discussed. In this work, $R_{\mathrm{GW}}=1000 V_{\mathrm{P}} / M_{\mathrm{W}}$, in which $V_{\mathrm{P}}$ is the cumulative volume of the produced $\mathrm{CH}_{4} ; M_{\mathrm{W}}$ represents the cumulative mass of the produced water. $R_{\mathrm{GW}}$ is a relative criterion to assess the performance of gas production. The hydration number of the hydrate in this work is 6 . If the produced gas and water are just originated from hydrate dissociation, $R_{\mathrm{GW}}$ is calculated to be 207 in standard state. However, $R_{\mathrm{GW}}$ is less than 8 in this work, indicating that a substantial quantity of the produced water stems from the free water in the reservoir.

As shown in Figure 5, during the first 40 days of depressurization in two wells, $R_{\mathrm{GW}}$ decreases slightly. In the injection process ( $\mathrm{J} 1$ and $\mathrm{J} 2$ are the beginning of the injection process), $R_{\mathrm{GW}}$ appears a local minimum point $\mathrm{K} 1$ ( $t=77$ day) and a local maximum point $\mathrm{L} 1$ ( $t=124$ day). From $\mathrm{J} 1$ to $\mathrm{K} 1$, $R_{\mathrm{GW}}$ drops as the warm brine is injected into the reservoir, and then increases because that hydrate is rapidly dissociated under the synergetic driving force of depressurization, thermal stimulation, and inhibitor stimulation. After reaching the maximum point $\mathrm{L} 1, R_{\mathrm{GW}}$ keeps monotonically decreasing until the end of the simulation due to the continuous increase of water production and the decrease of gas production. 
Figure 5. Evolution of the energy efficiency $\eta$, the gas-to-water ratio $R_{\mathrm{GW}}$, and their dependence on the salinity of the injected brine during hydrate dissociation.

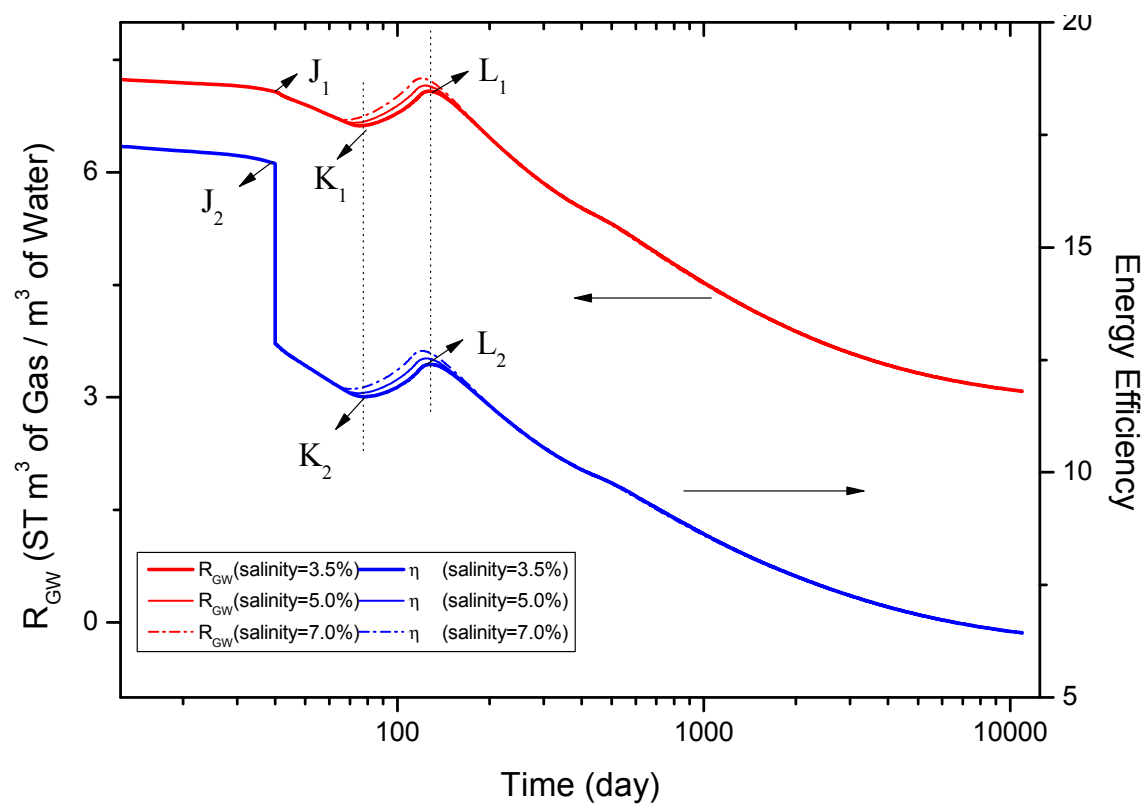

Another important parameter to evaluate the commercial profit of natural gas hydrate exploitation is the energy efficiency $\eta$. Figure 5 shows the evolution of $\eta$ in the process of hydrate dissociation with warm brine stimulation combined depressurization. The calculation method of $\eta$ is shown in the following equation [28]:

$$
\eta=\Delta H_{C} /(W+Q)
$$

In the equation, $\Delta H_{\mathrm{c}}$ is the total combustion enthalpy of methane $\left(1 \mathrm{~atm}, 25^{\circ} \mathrm{C}, 889.6 \mathrm{~kJ} / \mathrm{mol}\right)$. W is the energy used for pumping the produced fluids from the well to the ground. $Q$ is the total heat injected into the reservoir [28]. Meanwhile, $Q$ can be explained as $C_{\operatorname{minj}} \Delta T$, here $C$ stands for the specific of water $(4.2 \mathrm{~kJ} / \mathrm{kg} / \mathrm{K})$; minj represents the mass of the injected water; the water is assumed to be heated from $20^{\circ} \mathrm{C}$ to $28^{\circ} \mathrm{C}$.

It is evident in Figure 5 that the change trend of $\eta$ is almost similar to that of $R_{\mathrm{GW}}$, which is characterized by appearing two extreme points synchronously. $\eta$ is higher in the depressurization process than that in the injection process, which is because that the injected heat plays a leading role in $\eta$.

There is a sharp decline of $\eta$ at the 41 st day because of the warm brine injection. During the injection process, the maximum of $\eta$ is about 12.4 (point L2). After reaching the maximum point, $\eta$ gradually declines to about 6.5 and keeps a steady level until the end of simulation. In spite of the large amount of the produced water in this work, $\eta$ is higher than 6 in the whole dissociation process. In this work, the brine is just heated to $28{ }^{\circ} \mathrm{C}$. The high $\eta$ indicates that the warm brine (rather than hot brine) can improve energy utilization because of the low energy demand to heat the injected brine and the low energy loss in the injection process. In general, the production performance in the marine hydrate reservoir of the SCS with the warm brine stimulation combined depressurization seems to have good economic benefit due to the results of high gas production rate and high energy efficiency. 


\subsection{Spatial Distribution of $S_{\mathrm{H}}, S_{\mathrm{G}}$ and $X_{\mathrm{S}}$}

Figures 6 and 7 display the evolution of $S_{\mathrm{H}}$ (hydrate saturation) distributions and $S_{\mathrm{G}}$ (gas saturation) distributions during hydrate dissociation. It is shown from Figures 6 and 7 that (i) during the initial 40 days, the hydrate is dissociated around the wells with limited cylindrical dissociation interfaces, and then the dissociation interfaces move forward (Figure 6b,c); (ii) the hydrate distribution region around the lower well is dissociated faster than that of the upper one (Figure 6c); (iii) after one year production, the hydrate located between the two wells is dissociated completely (Figure 6d); (iv) a dissociation interface emerges between the HBL and the underburden, and gradually merges with the cylindrical dissociation interface around the lower well (Figure 6d,e); (v) a similar dissociation interface occurs between the HBL and the overburden at about the 5th year (Figure 6e); (vi) limited secondary hydrate is formed in the front edge of the dissociation interface near the upper well in the initial 5 years, subsequently, some hydrate formed in the lower region of the hydrate reservoir (Figure 6b-h); (vii) the released gas accumulated around the frontier of the cylindrical dissociation interface (Figure 7b-e); (viii) the released gas nearly disappear after ten years exploitation (Figure 7f).

Figure 6. Evolution of the spatial distribution of $S_{\mathrm{H}}$ during hydrate dissociation (the Reference Case).

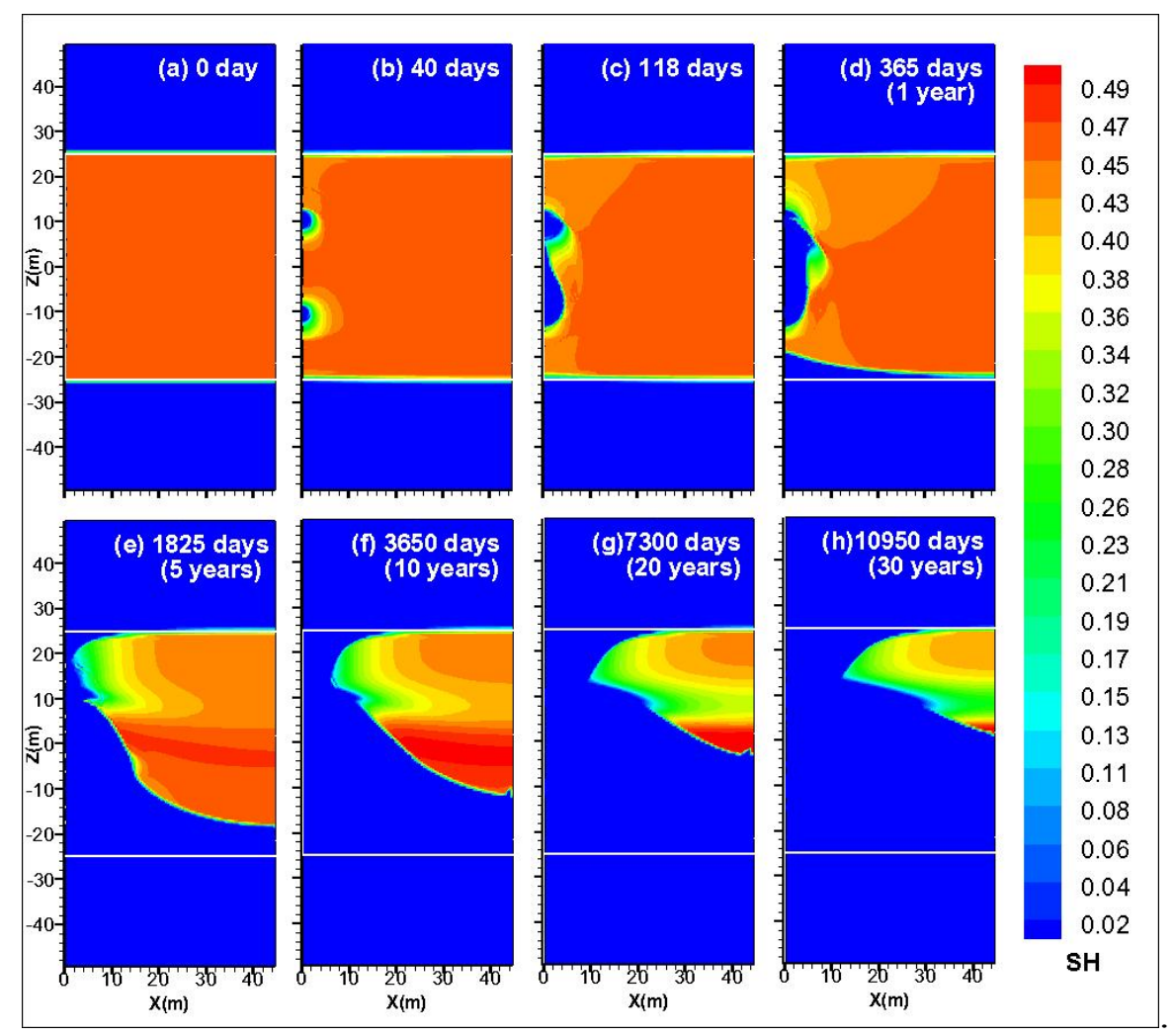

Of those, (i) and (iii) are the results of hydrate dissociation under the synergetic effect of depressurization, thermal stimulation, and inhibitor stimulation; (ii), (iv), and (v) are because on the one hand, the warm brine acts on the dissociation of hydrate located in the vicinity of the lower well, and on the other hand, the hydrate dissociation is influenced by the fluid flow from the overburden and the underburden; (vi) is because that the endothermic effect of hydrate dissociation causes the decrease 
of temperature near the dissociation interface, meanwhile, the released gas accumulates around this region, where the pressure condition is favorable for hydrate formation.

Figure 7. Evolution of the spatial distribution of $S_{\mathrm{G}}$ during hydrate dissociation (the Reference Case).

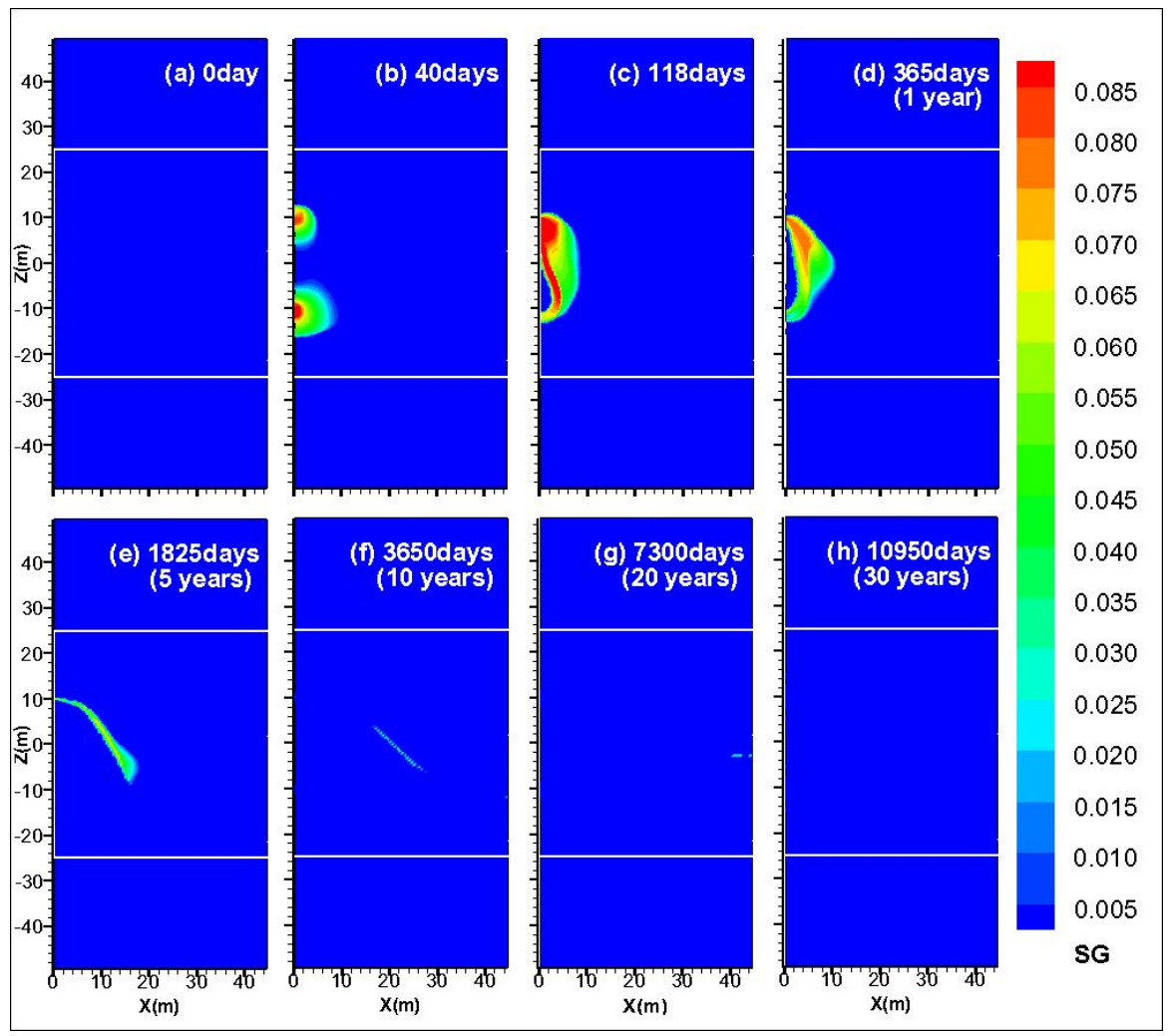

The secondary hydrate formation could reduce the effective permeability $k_{\text {eff }}$ and prevent the released gas rising. (vii) and (viii) are because that the released gas is pumped out from the upper well as the dissociation interface enlarges. The hydrate between the two wells is dissociated completely after about 118 days. A channel connects the two wells as the dissociation interface expands. And then the injected warm brine tends to be produced from the upper well directly, which further results in the gas accumulation in the vicinity of the upper well. The interspace between the two wells weakens the heat conduction to the inner part of the HBL, and decreases the rate of gas releasing.

Figure 8 shows the evolution of the distributions of salt concentration $X_{\mathrm{S}}$ (the mass fraction of salt $X_{\mathrm{S}}$ in the aqueous phase) in the entire hydrate reservoir. As shown in Figure $8, X_{\mathrm{S}}$ decrease in the hydrate dissociation area in the initial 40 days, which is due to the dilution effect of the free water released from the hydrate. As the injection process starts, the saline water from the overburden and underburden (both of them are permeable boundary) penetrates into the HBL under the effect of the depressurization, causing the increase of the higher $X_{\mathrm{S}}$ region. The $X_{\mathrm{S}}$ distribution in the vicinity of the wells on one hand increases with the influence of the injected brine, on the other hand decreases under the effect of the dilution. 
Figure 8. Evolution of the spatial distribution of $X_{\mathrm{S}}$ during hydrate dissociation (the Reference Case).

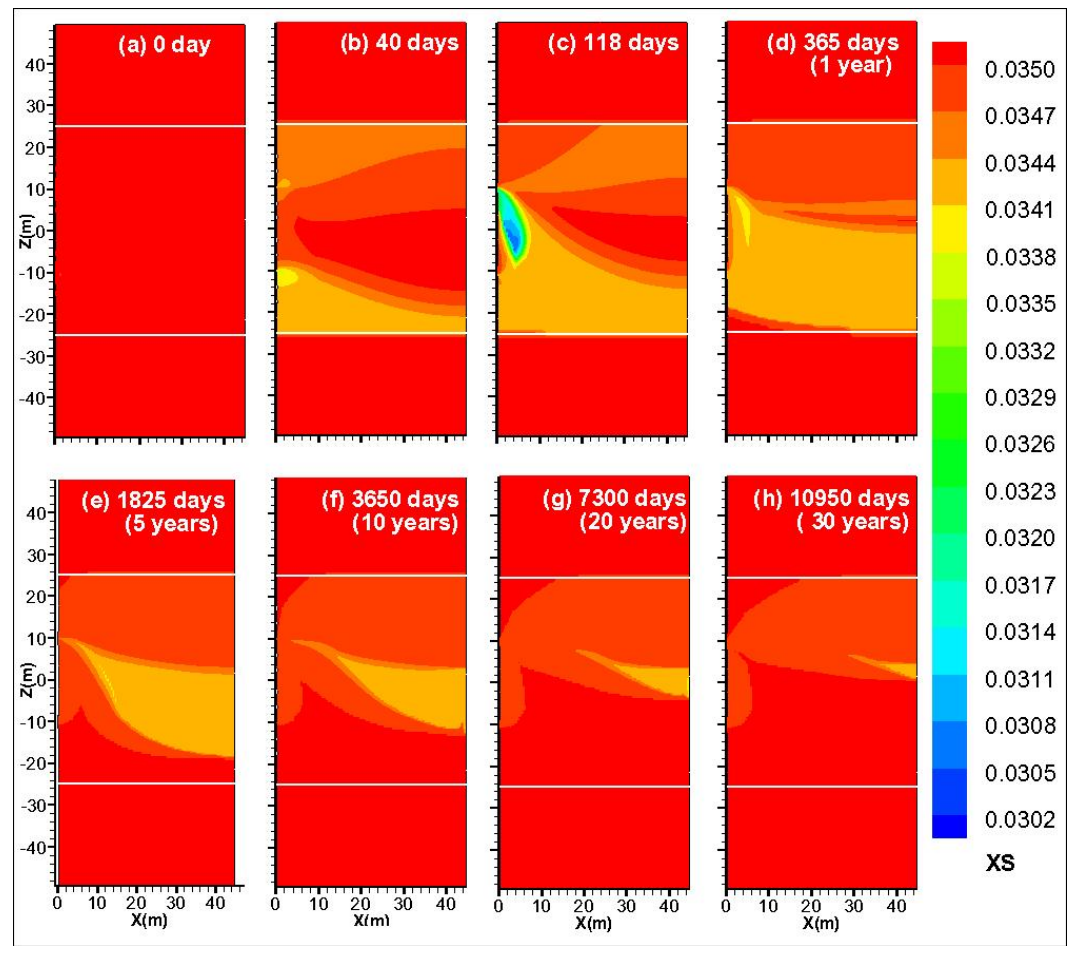

\subsection{Spatial Distribution of $P$ and $T$}

Figure 9 shows the change of the pressure distributions over time in the whole hydrate deposit. The area between the white lines stands for the HBL. As can be seen in Figure 9, (i) there is a cylindrical pressure gradient around the well in the initial 40 days (Figure 9b); (ii) the depressurization trend moves up over time (Figure 9b-h); (iii) the pressure gradient decreases gradually (Figure 9b-h); (iv) the pressure distribution in the hydrate reservoir changes slowly from the 5th year to the 30th year (Figure 9e-h); (v) there are inflection points of pressure distribution on the white line between the overburden and the HBL (Figure $9 d-h$ ). Of those, (i) results from the simultaneous depressurization in the two wells; (ii) and (iii) are caused by the flow of the released fluid and the permeability of the boundary; (iv) is because that the gas-liquid flow field is relatively stable after the production well and injection well are connected; (v) originates from the different effective permeabilities of the overburden and the HBL.

Figure 10 demonstrates the evolution of the temperature distributions in the entire hydrate reservoir. As shown in Figure 10: (i) the temperature around the wells decreases because of the endothermic effect of hydrate dissociation (Figure 10b); (ii) the temperature declines near the top boundary of the HBL, and increases near the bottom boundary caused by the effect of fluids flow (Figure 10b); (iii) as the injection process starts, the temperature around the lower well increases and the heat is transferred deep into the HBL under the effect of the temperature gradient(Figure 10c-h); (iv) as soon as the hydrate between the two wells is dissociated completely, the temperature near the upper well rises because the injected warm brine flows up (Figure 10d-h); (v) the thermal gradient spreads further into the HBL over time due to the effect of fluids flow(Figure 10d-h); (vi) the temperature distribution in the whole hydrate reservoir changes slowly from 5 to 30 years because the fluid flow situation keeps 
stable during this period (Figure 10e-h). It is evident from Figure 10c- $\mathrm{h}$ that the temperature distributions in the overburden and underburden nearly keep unchangeable, which is attributed to that abundant saline water flow from the overburden and underburden to the initial HBL area.

Figure 9. Evolution of the spatial distribution of $P$ during hydrate dissociation (the Reference Case).

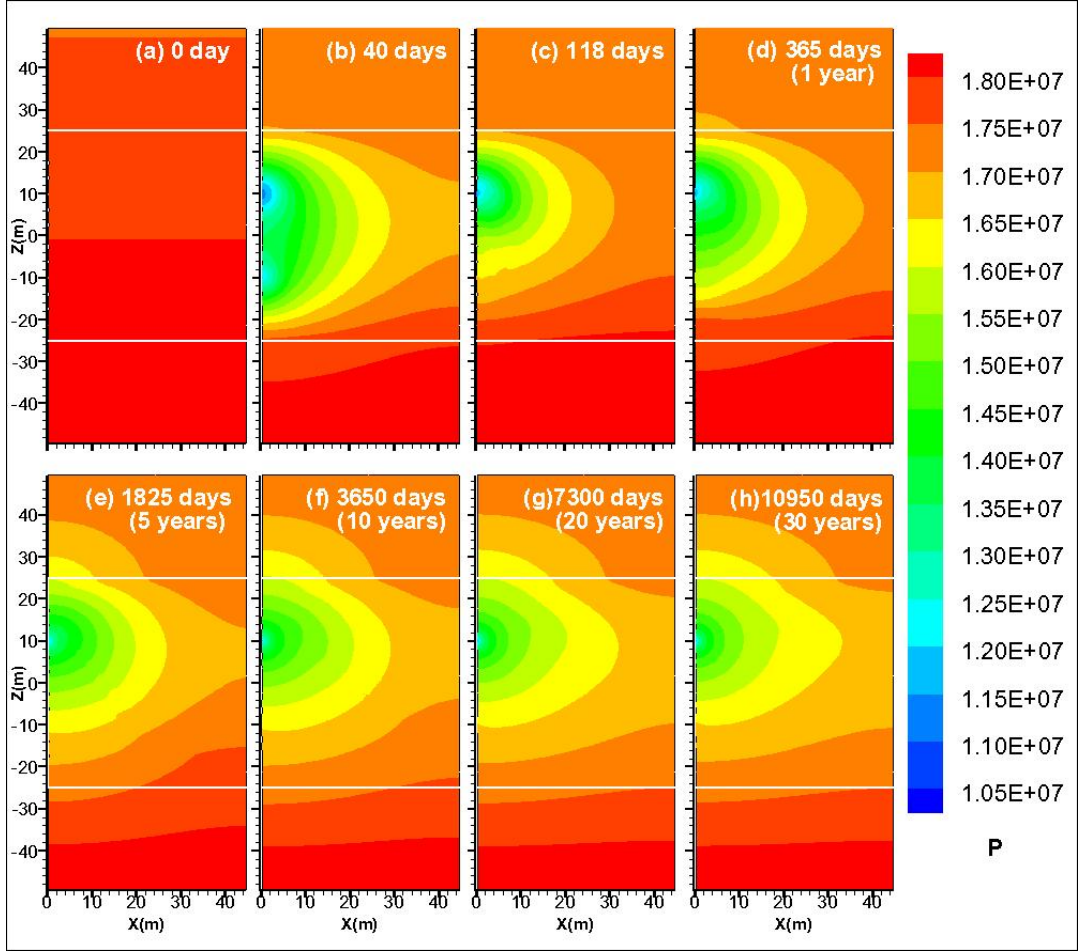

Figure 10. Evolution of the spatial distribution of $T$ during hydrate dissociation (the Reference Case).

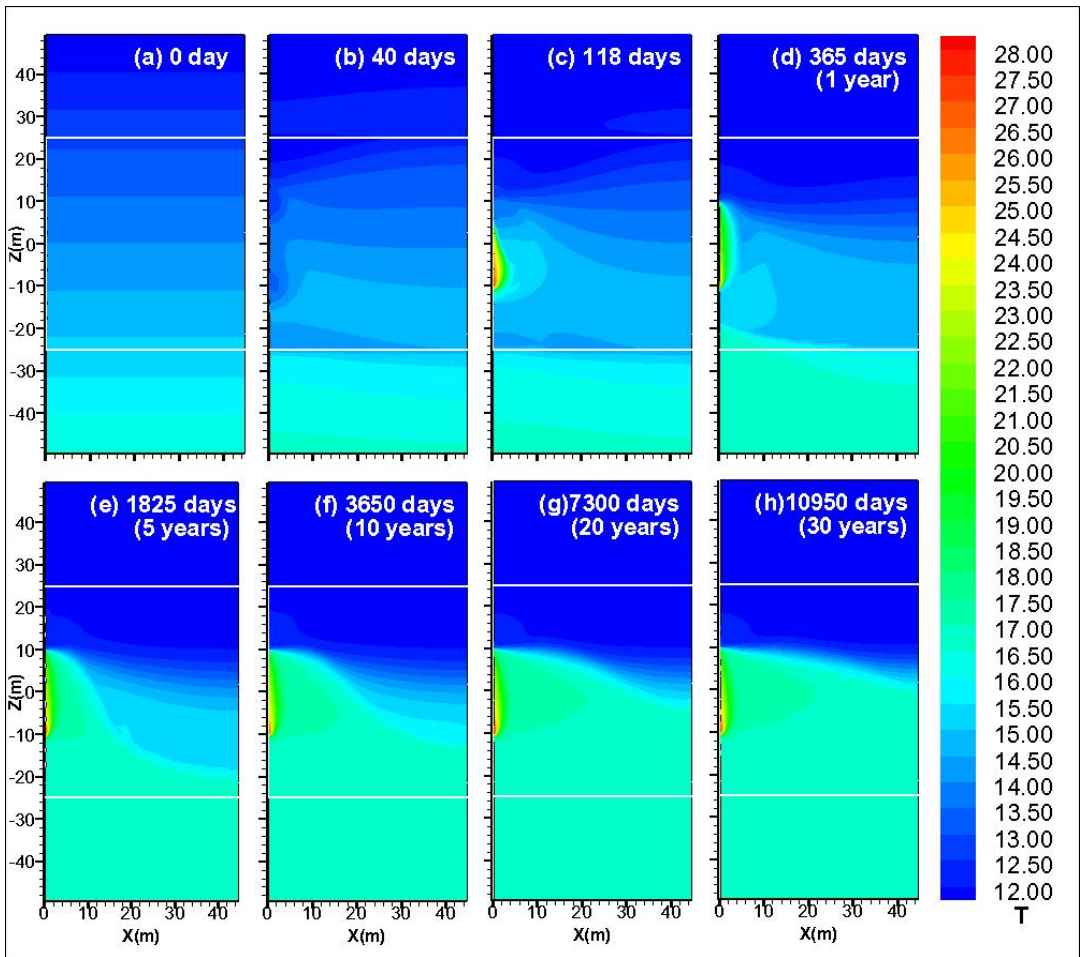




\subsection{Sensitivity Analyses}

In this work, different cases are implemented to investigate the sensitivities of gas production on the temperature of the injected brine $T_{\mathrm{W}}$, the salinity of the injected brine, and the intrinsic permeability $k$ of the hydrate reservoir.

\subsubsection{Sensitivity to the Temperature of the Injected Water $T_{\mathrm{W}}$}

Figure 11 shows the evolution of $Q_{\mathrm{PT}}, Q_{\mathrm{R}}$, and $Q_{\mathrm{W}}$ over time with different temperatures of the injected brine $\left(T_{\mathrm{W}}=28{ }^{\circ} \mathrm{C}, 90{ }^{\circ} \mathrm{C}\right)$. In the reference case, $T_{\mathrm{W}}$ is $28{ }^{\circ} \mathrm{C}$. The rest parameters between these two cases are same.

Figure 11. Evolution of $Q_{\mathrm{PT}}, Q_{\mathrm{R}}, Q_{\mathrm{W}}$, and their dependence on the temperature of the injected brine during hydrate dissociation.

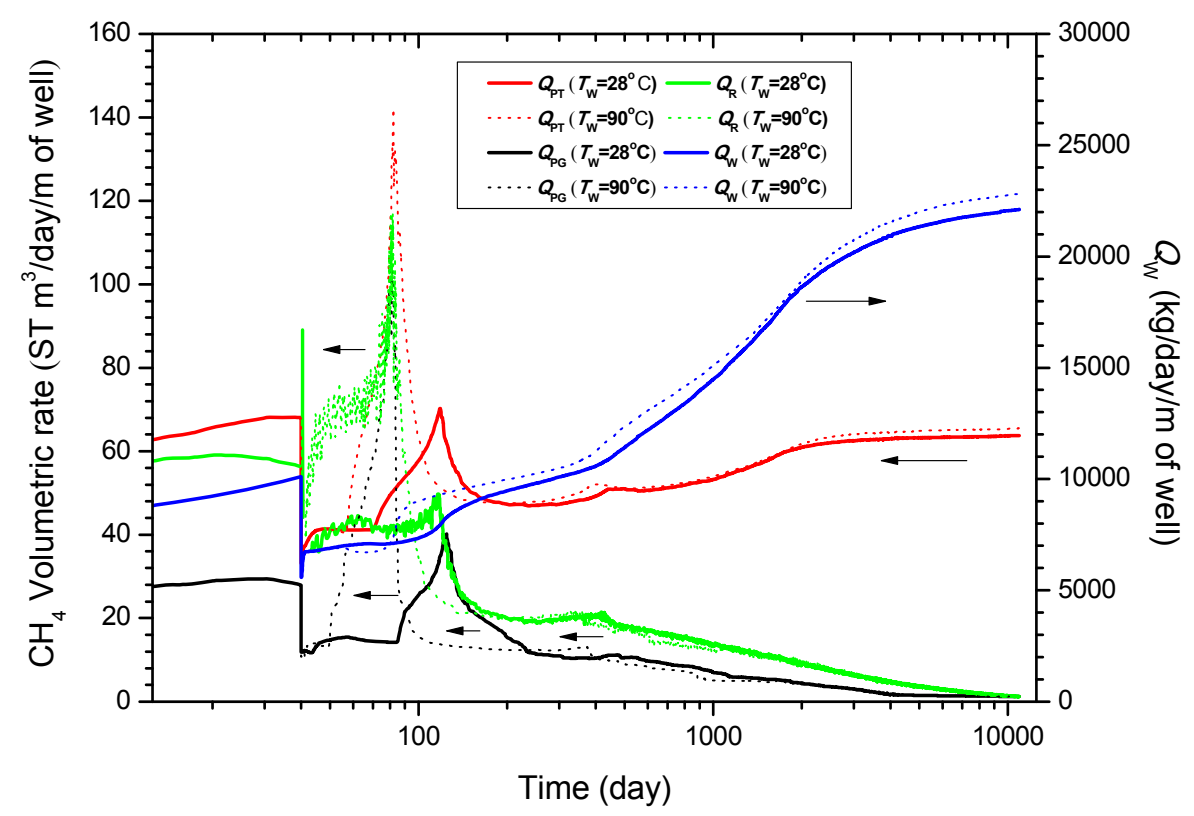

When $T_{\mathrm{W}}$ increases from $28{ }^{\circ} \mathrm{C}$ to $90{ }^{\circ} \mathrm{C}$, it costs just 42 days (accounts for $35 \%$ of the reference case) to dissociate the hydrate blocking the region between the two wells. The peak value of $Q_{\text {PT }}$ is $142.12 \mathrm{ST} \mathrm{m}^{3} /$ day $/ \mathrm{m}$ of well when $T_{\mathrm{W}}$ is $90{ }^{\circ} \mathrm{C}$, which is 2.02 times larger than that of the reference case. The warm brine flows to the production well directly after the two wells are connected which diminishing the impact of heat convection and conduction. Thus, at the later stage of exploitation, the distinction of hydrate dissociation and gas production is mild between the two different $T_{\mathrm{W}}$ cases. $Q_{\mathrm{W}}$ increases with the enhancement of $T_{\mathrm{W}}$ as well. This is because more hydrate is dissociated under the stimulation of high temperature brine.

Figure 12 displays the dependence of $R_{\mathrm{GW}}$ and $\eta$ on $T_{\mathrm{W}} . R_{\mathrm{GW}}$ grows corresponding to the rise of $Q_{\mathrm{PT}}$ in the higher $T_{\mathrm{W}}$ case, which is because increasing the temperature of the injected brine can strengthen the heat-transfer effect. This phenomenon further results in advantageous gas production rate. 
Figure 12. Evolution of the energy efficiency $\eta$, the gas-to-water ratio $R_{\mathrm{GW}}$, and their dependence on the temperature of the injected brine during hydrate dissociation.

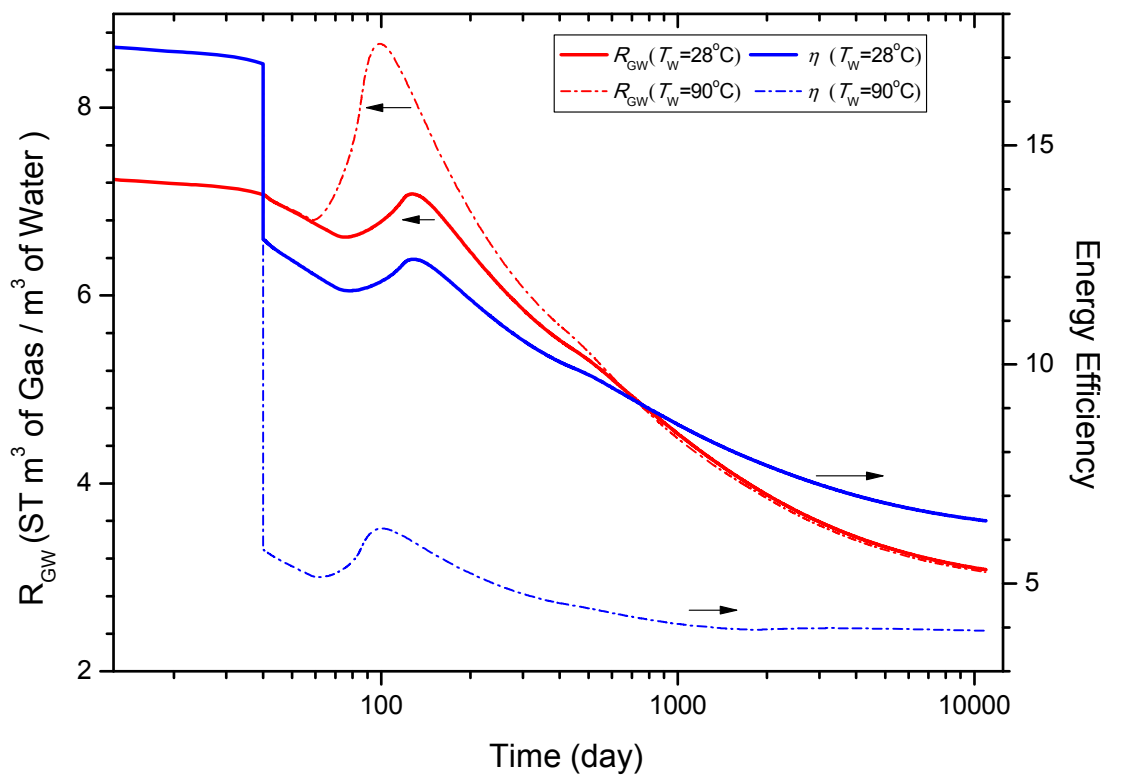

Unfortunately, the other criterion $\eta$ declines remarkably with the enhancement of $T_{\mathrm{W}}$, which is uneconomical for hydrate exploitation. This is because the higher $T_{\mathrm{W}}$ case needs more energy to heat the injected brine and causes more energy loss in the cause of injecting the brine.

\subsubsection{Sensitivity to the Salinity of the Injected Water}

Figures 4 and 5 show the evolution of $Q_{\mathrm{PT}}, Q_{\mathrm{R}}, Q_{\mathrm{W}}, R_{\mathrm{GW}}, \eta$, and their dependence on the salinity of the injected brine, respectively. In the reference case, the salinity of the injected brine is $3.5 \%$. Except for the different salinity of the injected brine, the other system conditions in the three cases remained the same.

As shown in Figure 4, the profiles of $Q_{\mathrm{PT}}, Q_{\mathrm{R}}$, and $Q_{\mathrm{W}}$ from different cases are similar in the whole simulation process. The differences among the three cases appear as the injection process starts. Figure 4 shows that the higher the salinity of the injected brine is, the faster the $Q_{\mathrm{PT}}$ and $Q_{\mathrm{R}}$ become, which is in good agreement with the experimental investigation by Li et al.[10].

The model of the inhibitor effects on hydrate equilibrium can be simplified by the following equation [29]:

$$
\Delta T_{D}=\Delta T_{D, r} \frac{\ln \left(1-x_{A}^{i}\right)}{\ln \left(1-x_{A, r}^{i}\right)}
$$

where $x_{A}^{i}$ is the mole fraction of the inhibitor in the aqueous phase; $x_{A, r}^{i}$ is the reference mole fraction of the inhibitor in the aqueous phase $[\mathrm{K}] ; \Delta T_{D}$ is the inhibitor-induced temperature depression $[\mathrm{K}] ; \Delta T_{D, r}$ is the temperature depression at the reference mole fraction $x_{A, r}^{i}$. As can be seen from Equation (2), when the $x_{A}^{i}$ (the salinity of the injected water) gets larger, it is more easily to break the hydrate equilibrium.

Once the hydrate blocking area between the two wells is dissociated completely, the distinction among the three cases gets smaller and almost fades away after 205 days injection. This is because that 
the injected warm brine can be pumped out through the cavity between the two wells to the upper production well directly, which weakens the inhibitor effects on the hydrate far from the injected well.

The injection rates of the brine are the same and the distinction of hydrate dissociation rates is little among the three cases. Thus the difference in $Q_{\mathrm{W}}$ is very small when the salinity of the injected brine increases from $3.5 \%$ to $7.0 \%$. As shown in Figure 5, the gas-to-water ratio and the energy efficiency can be enhanced by increasing the salinity of the injected brine before the two horizontal wells are connected. Subsequently, the value of $Q_{\mathrm{W}}$ and $\eta$ among the three cases almost keep the same, which is in line with the changes of gas and water production.

\subsubsection{Sensitivity to the Intrinsic Permeability $k$ of the Hydrate Reservoir}

The effect of different intrinsic permeabilities of the hydrate reservoir on the production performance is also investigated. Except for the different intrinsic permeabilities of the two cases, the other operation conditions remain the same.

Figures 13 and 14 show the dependences of $Q_{\mathrm{PT}}, Q_{\mathrm{R}}, Q_{\mathrm{W}}, R_{\mathrm{GW}}$, and $\eta$ on the intrinsic permeability $k$ of the hydrate reservoir, respectively. Reducing $k$ from $75 \mathrm{mD}$ to $5 \mathrm{mD}$ causes a dramatic decline of gas production. $Q_{\mathrm{PT}}$ reaches the maximum value $\left(70.19 \mathrm{ST} \mathrm{m}^{3} /\right.$ day $/ \mathrm{m}$ of well) when the two wells are totally connected in the reference case. However, the maximum value of $Q_{\text {PT }}$ is just $9.86 \mathrm{ST} \mathrm{m} /$ day $/ \mathrm{m}$ of well when $k$ drops to $5 \mathrm{mD}$. In the later stage of simulation, $Q_{\mathrm{PT}}$ of the reference case is about 16.7 times larger than that of the lower $k$ case. Moreover, the water production rate in the lower $k$ case drops dramatically compared with the reference case. This is because when the intrinsic permeabilities become small, it's more difficult for the fluids flow in the hydrate reservoir, which further decreases the production rate of gas/water.

Figure 13. Evolution of $Q_{\mathrm{PT}}, Q_{\mathrm{R}}, Q_{\mathrm{W}}$, and their dependence on the intrinsic permeability $k$ of the hydrate reservoir during hydrate dissociation.

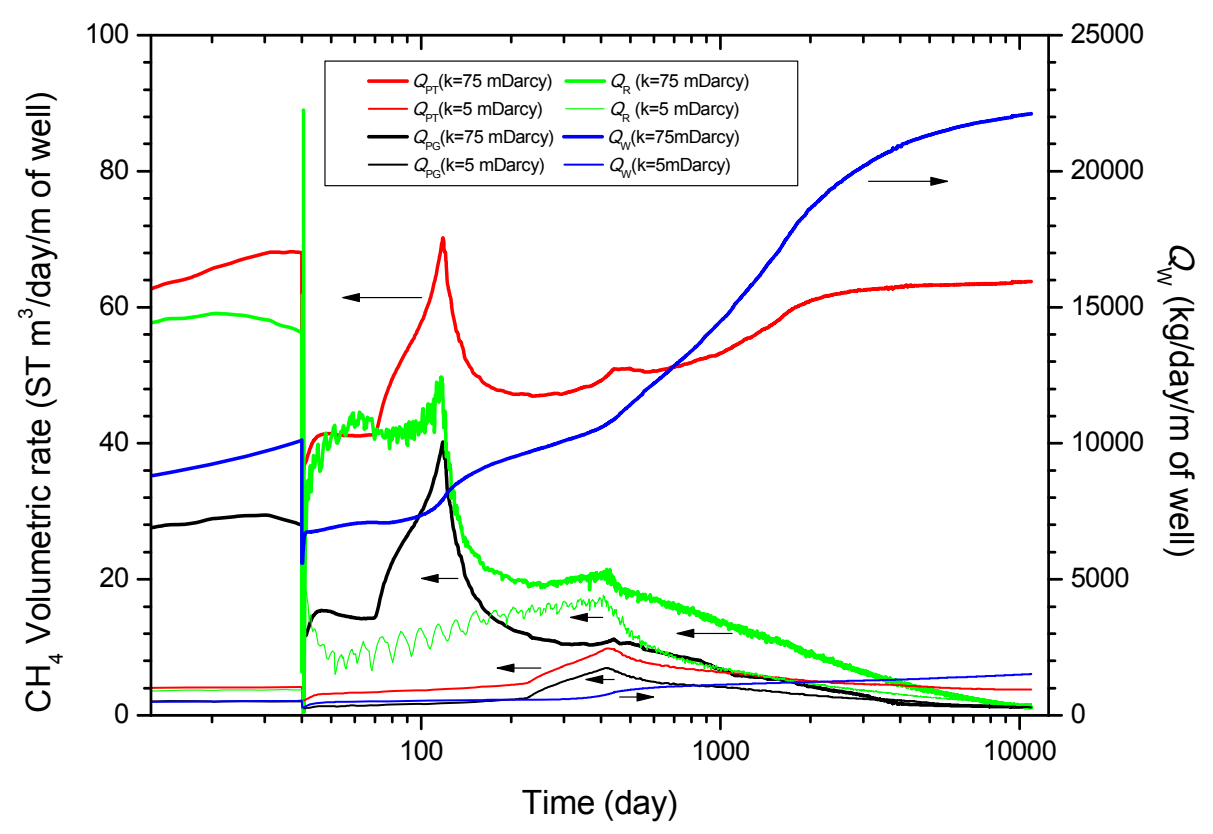


Figure 14. Evolution of the energy efficiency $\eta$, the gas-to-water ratio $R_{\mathrm{GW}}$, and their dependence on the intrinsic permeability $k$ of the hydrate reservoir during hydrate dissociation.

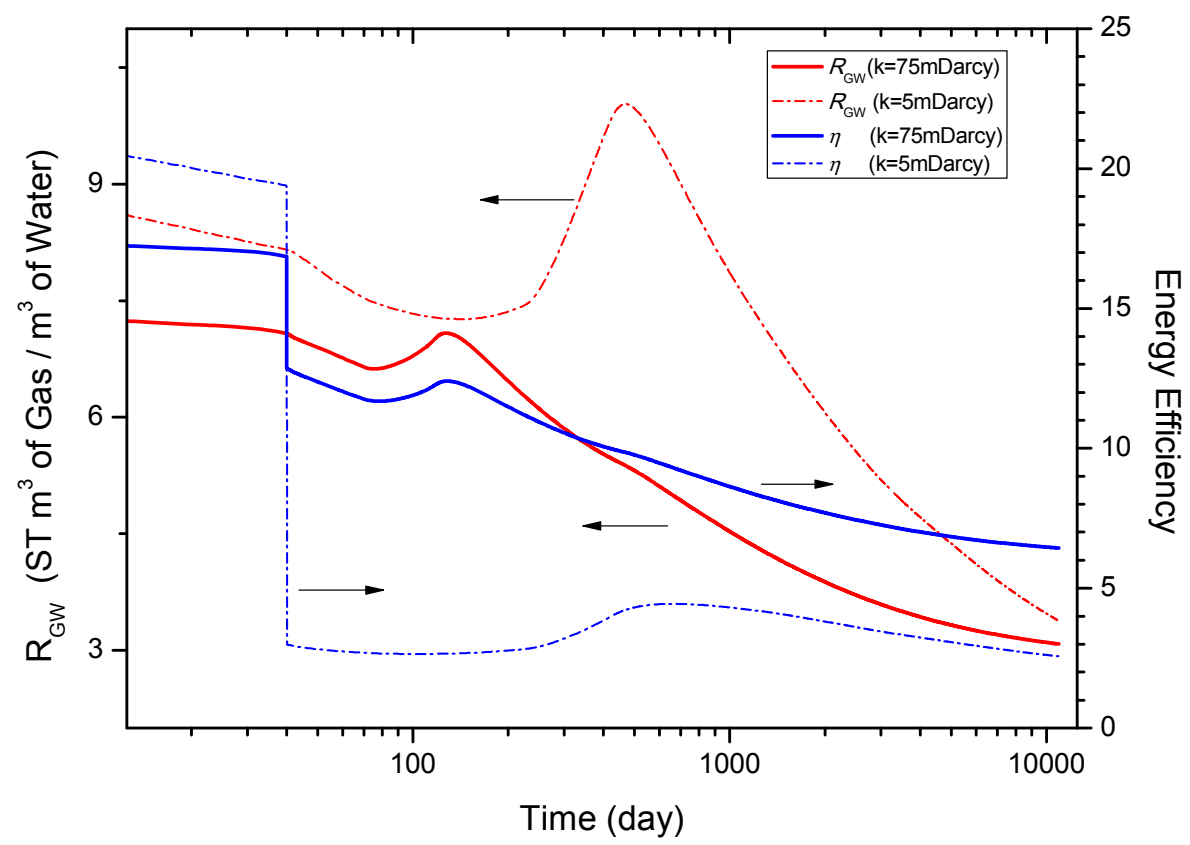

Another noteworthy phenomenon is that $Q_{\mathrm{R}}$ is larger than $Q_{\mathrm{PT}}$ in the initial 1438 days. It means the produced gas mainly originates from the released gas from the hydrate reservoir rather than the gas dissolved in the produced water in the lower $k$ case.

As shown in Figure 14, because of the substantial reduction of water production rate, $R_{\mathrm{GW}}$ in the lower $k$ case is evidently larger than that in the reference case. The other criterion $\eta$ is much lower than that of the reference case, which is uneconomic for gas production.

\section{Conclusions}

Based on the available limited data about the South China Sea, a marine hydrate reservoir model is established in order to investigate the gas production performance under warm brine stimulation combined depressurization with dual horizontal wells. The following conclusions can be drawn:

(1) A dual horizontal well layout has been considered as the well configuration for this work. During the exploitation process, the upper well is regarded as the production well. A constant flow rate of warm brine is simultaneously injected into the hydrate reservoir through the lower well. For avoiding the pressure of the area around the lower well increase to an extremely high level by continuous injection at the start of the production process, a period of constantpressure production in the lower well to decompose the hydrate and free the pores around the well is needed.

(2) During the depressurization production stage, two cylindrical dissociation fronts exist around the two wells. As the injection process starts, the dissociation fronts enlarge with the injection of warm brine. The gas production rate increases when the hydrate between the two wells is gradually dissociated. Meanwhile, $Q_{\mathrm{PT}}$ and $Q_{\mathrm{R}}$ reach the peak value when the two wells are connected completely. A dissociation interface emerges between the HBL and the underburden, 
and then gradually merges with the cylindrical dissociation interface around the lower well. A similar dissociation interface occurs in the upper well and the overburden lately.

(3) In the reference case, $Q_{\mathrm{PT}}$ exceeds $Q_{\mathrm{R}}$ and $Q_{\mathrm{PG}}$ in the whole production of 30 years, indicating that most of the produced gas comes from the $\mathrm{CH}_{4}$ dissolved in the water rather than from the free gas. A maximum value $\left(17.3 \mathrm{ST} \mathrm{m}^{3} / \mathrm{day} / \mathrm{m}\right)$ of $Q_{\mathrm{PT}}$ is obtained before a decline starts at the 118 th day. The variation of $Q_{\mathrm{R}}$ is similar to that of $Q_{\mathrm{PT}}$. The average gas production rate $Q_{\text {avg }}$ is about $1.23 \times 10^{5} \mathrm{ST} \mathrm{m}^{3} /$ day for a $1000 \mathrm{~m}$-long well with spacing of $90 \mathrm{~m}$, which can obtain the same order of magnitude compared with the commercially viable production rate. The corresponding water production rate $Q_{\mathrm{W}}$ is about $3.98 \times 10^{7} \mathrm{~kg} /$ day which is massive. Furthermore, it causes a relative low level of $R_{\mathrm{GW}}$ (from 3.08 to 7.35). The other criterion $\eta$ gets the range of 6.43 to 17.5 . The simulation results provide economical feasibility of the warm brine stimulation combined depressurization method from the point of high level of energy efficiency.

(4) The analysis of sensitivity to the temperature of the injected brine indicates that increasing $T_{\mathrm{W}}$ can enhance $Q_{\mathrm{PT}}, Q_{\mathrm{R}}$, and $R_{\mathrm{GW}}$ remarkably when the injection process starts. However, the advantage gradually disappears as the hydrate blocking the channel of the two wells is dissociated totally. The analysis of sensitivity to the salinity of the injected brine comes to the conclusion that the larger the $X_{\mathrm{S}}$ is, the faster the gas production rate is. But this advantage gradually fades away after the two wells are connected. Consequently, some practical methods such as enlarging the distance between the two wells may be taken into account to make the warm brine injected deep into the hydrate reservoir.

(5) Sensitivity analysis shows that the gas and water production are strongly dependent on the intrinsic permeability of the hydrate reservoir. The gas and water production rates decrease when the intrinsic permeability decline from $75 \mathrm{mD}$ to $5 \mathrm{mD}$. The energy efficiency $\eta$ also gets an evident decrease with the reduction of $\mathrm{k}$, on the other hand, an obvious enhancement of the gas-to-water ratio $R_{\mathrm{GW}}$ can be observed. When $k$ decreases to $5 \mathrm{mD}, Q_{\mathrm{R}}$ is larger than $Q_{\mathrm{PT}}$ in the initial 1475 days, suggesting that the produced gas mainly comes from the released gas.

\section{Acknowledgments}

This work was supported by National Science Fund for Distinguished Young Scholars of China (51225603), National Natural Science Foundation of China (51076155, 5100408951276182 , and 51106160), Key Arrangement Programs of the Chinese Academy of Sciences (KGZD-EW-301-2) and Science \& Technology Program of Guangzhou (2012J5100012), which are gratefully acknowledged.

\section{Conflicts of Interest}

The authors declare no conflict of interest. 


\section{References}

1. Shiraki, M. Physical characterization of TRK-720 hydrate, the very late Antigen-4 (VLA-4) inhibitor, as a solid form for inhalation: Preparation of the hydrate by solvent exchange among its solvates and mechanistical considerations. J. Pharm. Sci. 2010, 99, 3986-4004.

2. Sloan, E.D.; Koh,C.A. Clathrate Hydrates of Natural Gases, 3rd ed.; CRC Press: Boca Raton, FL, USA, 2008.

3. Moridis, G.J. Challenges, uncertainties and issues facing gas production from gas hydrate deposits. SPE Reserv. Eval. Eng. 2011, 14, 76-112.

4. Li, G.; Li, B.; Li, X.S.; Zhang, Y.; Wang, Y. Experimental and numerical studies on gas production from methane hydrate in porous media by depressurization in pilot-scale hydrate simulator. Energy Fuels 2012, 26, 6300-6310.

5. Zhao, J.F.; Yu, T.; Song, Y.C.; Liu, D.; Liu, W.G.; Liu, Y.; Yang, M.J.; Ruan, X.K.; Li, Y.H. Numerical simulation of gas production from hydrate deposits using a single vertical well by depressurization in the Qilian Mountain permafrost, Qinghai-Tibet Plateau, China. Energy 2013, $52,308-319$.

6. Li, X.S.; Wang, Y.; Duan, L.P.; Li, G.; Zhang, Y.; Huang, N.S.; Chen, D.F. Experimental investigation into methane hydrate production during three-dimensional thermal huff and puff. Appl. Energy 2012, 94, 48-57.

7. Mohammadi, A.H.; Richon, D. Phase equilibria of hydrogen sulfide and carbon dioxide simple hydrates in the presence of methanol, (methanol plus $\mathrm{NaCl}$ ) and (ethylene glycol plus $\mathrm{NaCl}$ ) aqueous solutions. J. Chem. Thermodyn. 2012, 44, 26-30.

8. Moridis, G.J.; Collett, T.S.; Dallimore, S.R.; Satoh, T.; Hancock, S.; Weatherill, B. Numerical studies of gas production from several $\mathrm{CH}_{4}$ hydrate zones at the Mallik site, Mackenzie Delta, Canada. J. Petrol. Sci. Eng. 2004, 43, 219-238.

9. Li, G.; Tang, L.; Huang, C.; Feng, Z.; Fan, S. Thermodynamic evaluation of hot brine stimulation for natural gas hydrate dissociation. J. Chem. Ind. Eng. (China) 2006, 57, 2033-2038.

10. Li, X.S.; Wan, L.H.; Li, G.; Li, Q.P.; Chen, Z.Y.; Yan, K.F. Experimental investigation into the production behavior of methane hydrate in porous sediment with hot brine stimulation. Ind. Eng. Chem. Res. 2008, 47, 9696-9702.

11. Moridis, G.J.; Reagan, M.T.; Boyle, K.L.; Zhang, K. Evaluation of the gas production potential of some particularly challenging types of oceanic hydrate deposits. Transp. Porous Media 2011, 90, 269-299.

12. Moridis, G.J.; Collett, T.S.; Boswell, R.; Kurihara, M.; Reagan, M.T.; Koh, C.; Sloan, E.D. Toward production from gas hydrates: current status, assessment of resources, and simulation-based evaluation of technology and potential. SPE Reserv. Eval. Eng. 2009, 12, 745-771.

13. Japan Taps "Fiery Ice" Fuel from Seabed. Available online: http://www.newscientist.com/ blogs/shortsharpscience/2013/03/japan-taps-methane-hydrate-fro.html (accessed on 13 March 2013).

14. Boswell, R.; Frye, M.; Shelander, D.; Shedd, W.; McConnelle, D.R.; Cook, A. Architecture of gas-hydrate-bearing sands from Walker Ridge 313, Green Canyon 955, and Alaminos Canyon 21: Northern deepwater Gulf of Mexico. Mar. Pet. Geol. 2012, 34, 134-149. 
15. Myshakin, E.M.; Gaddipati, M.; Rose, K.; Anderson, B.J. Numerical simulations of depressurization-induced gas production from gas hydrate reservoirs at the Walker Ridge 313 site, northern Gulf of Mexico. Mar. Petrol. Geol. 2012, 34, 169-185.

16. Trung, N.N. The gas hydrate potential in the South China Sea. J. Petrol. Sci. Eng. 2012, 88-89, $41-47$.

17. Liu, H.L.; Yao, Y.J.; Deng, H. Geological and geophysical conditions for potential natural gas hydrate resources in southern South China Sea waters. J. Earth Sci. (China) 2011, 22, 718-725.

18. Wang, C.J.; Du, D.W.; Zhu, Z.W.; Liu, Y.G.; Yan, S.J.; Yang, G. Estimation of potential distribution of gas hydrate in the northern South China Sea. Chin. J. Oceanol. Limn. 2010, 28, 693-699.

19. Li, G.; Moridis, G.J.; Zhang, K.; Li, X.S. The use of huff and puff method in a single horizontal well in gas production from marine gas hydrate deposits in the Shenhu Area of South China Sea. J. Petrol Sci. Eng. 2011, 77, 49-68.

20. Su, Z.; Moridis, G.J.; Zhang, K.; Wu, N. A huff-and-puff production of gas hydrate deposits in Shenhu area of South China Sea through a vertical well. J. Petrol. Sci. Eng. 2012, 86-87, 54-61.

21. Yao, B.C. The gas hydrate in the South China Sea. J. Trop. Oceanogr. 2001, 20, 20-28.

22. Wang, S.; Yan, W.; Song, H. Mapping the thickness of the gas hydrate stability zone in the South China Sea. Terr. Atmos. Ocean Sci. 2006, 17, 815-828.

23. Moridis, G.J.; Reagan, M.T. Strategies for Gas Production From Oceanic Class 3 Hydrate Accumulations. In Proceedings of the OTC 18865, 2007 Offshore Technology Conference, Houston, TX, USA, 30 April-3 May 2007.

24. Moridis, G.J.; Reagan, M.T.; Boyle, K.L.; Zhang, K. Evaluation of the Gas Production Potential of Challenging Hydrate Deposits. In TOUGH Symposium; Lawrence Berkeley National Laboratory: Berkeley, CA, USA, 14-16 September 2009.

25. Li, X.S.; Zhang, Y.; Li, G.; Chen, Z.Y.; Wu, H.J. Experimental investigation into the production behavior of methane hydrate in porous sediment by depressurization with a novel three-dimensional cubic hydrate simulator. Energy Fuels 2011, 25, 4497-4505.

26. Konno, Y.; Masuda, Y.; Hariguchi, Y.; Kurihara, M.; Ouchi, H. Key factors for depressurization-induced gas production from oceanic methane hydrates. Energy Fuels 2010, 24, 1736-1744.

27. Moridis, G.J.; Reagan, M.T.; Zhang, K. The Use of Horizontal Wells in Gas Production from Hydrate Accumulations. In Proceedings of the 6th International Conference on Gas Hydrates (ICGH 2008), Vancouver, BC, Canada, 6-10 July 2008.

28. Li, X.S.; Li, B.; Li, G.; Yang, B. Numerical simulation of gas production potential from permafrost hydrate deposits by huff and puff method in a single horizontal well in Qilian Mountain, Qinghai province. Energy 2012, 40, 59-75.

29. Moridis, G.J.; Kowalsky, M.B.; Pruess, K. Tough+Hydrate v1.1 User's Manual: A Code for the Simulation of System Behavior in Hydrate-Bearing Geologic Media; Lawrence Berkeley National laboratory: Berkeley, CA, USA, 2009.

30. Wang, D.; Li, D.L.; Zhang, H.L.; Fan, S.S.; Zhao, H.B. Laboratory measurement of longitudinal wave velocity of artificial gas hydrate under different temperatures and pressures. Sci. China Ser. G Phy. Mech. Astron. 2008, 51, 1905-1913. 
31. Gamwo, I.K.; Liu, Y. Mathematical modeling and numerical simulation of methane production in a hydrate reservoir. Ind. Eng. Chem. Res. 2010, 49, 5231-5245.

32. Liu, Y.; Strumendo, M.; Arastoopour, H. Simulation of methane production from hydrates by depressurization and thermal stimulation. Ind. Eng. Chem. Res. 2009, 48, 2451-2464.

33. Yao, B.C.; Yang, M.Y.; Wu, S.G.; Wang, H.B. The gas hydrate resources in the China seas. Geoscience (China) 2008, 22, 333-341.

34. Van Genuchten, M.T. A closed-form equation for predicting the hydraulic conductivity of unsaturated soils. Soil Sci. Soc. Am. J. 1980, 44, 892-898.

35. Moridis, G.J.; Seol, Y.; Kneafsey, T.J. Studies of Reaction Kinetics of Methane Hydrate Dissociation in Porous Media. In Proceedings of the 5th International Conference on Gas Hydrate, Trondheim, Norway, 3-5 June 2005; pp. 1004-1014.

(C) 2013 by the authors; licensee MDPI, Basel, Switzerland. This article is an open access article distributed under the terms and conditions of the Creative Commons Attribution license (http://creativecommons.org/licenses/by/3.0/). 